\title{
Numerical simulation of condensation of sulfuric acid and water in a large two-stroke marine diesel engine
}

\author{
Karvounis, Nikolas; Pang, Kar Mun; Mayer, Stefan; Walther, Jens Honore
}

Published in:

Applied Energy

Link to article, DOI:

10.1016/j.apenergy.2017.11.085

Publication date:

2018

Document Version

Peer reviewed version

Link back to DTU Orbit

Citation (APA):

Karvounis, N., Pang, K. M., Mayer, S., \& Walther, J. H. (2018). Numerical simulation of condensation of sulfuric acid and water in a large two-stroke marine diesel engine. Applied Energy, 211, 1009-1020.

https://doi.org/10.1016/j.apenergy.2017.11.085

\section{General rights}

Copyright and moral rights for the publications made accessible in the public portal are retained by the authors and/or other copyright owners and it is a condition of accessing publications that users recognise and abide by the legal requirements associated with these rights.

- Users may download and print one copy of any publication from the public portal for the purpose of private study or research.

- You may not further distribute the material or use it for any profit-making activity or commercial gain

- You may freely distribute the URL identifying the publication in the public portal 


\title{
Numerical Simulation of Condensation of Sulfuric Acid and Water in a Large Two-stroke Marine Diesel Engine
}

\author{
Nikolas Karvounis ${ }^{\mathrm{a}}$, Kar Mun Panga,b, Stefan Mayer ${ }^{\mathrm{c}}$, Jens Honoré Walthera,d \\ ${ }^{a}$ Section for Fluid Mechanics, Coastal and Maritime Engineering, Department of \\ Mechanical Engineering, Technical University of Denmark, Nils Koppels Allé, 2800 Kgs. \\ Lyngby, Denmark \\ ${ }^{b}$ Section of Thermal Energy, Department of Mechanical Engineering, Technical University \\ of Denmark, Nils Koppels Allé, 2800 Kgs. Lyngby, Denmark \\ ${ }^{c}$ MAN Diesel \& Turbo, Teglholmsgade 41, 2450 Copenhagen SV, Denmark \\ ${ }^{d}$ Computational Science and Engineering Laboratory, ETH Zürich, Clausiusstrasse 33 \\ ETH-Zentrum, CH-8092 Zürich, Switzerland
}

\begin{abstract}
In the present study, three-dimensional (3D) computational fluid dynamics simulations are performed to examine the process of sulfuric acid $\left(\mathrm{H}_{2} \mathrm{SO}_{4}\right)$ and water $\left(\mathrm{H}_{2} \mathrm{O}\right)$ condensation in a large two-stroke marine diesel engine. A skeletal n-heptane chemical mechanism is coupled with a sulfur (S) subset to simulate the combustion process as well as the formation of sulfuric oxides $\left(\mathrm{SO}_{\mathrm{x}}\right)$ and $\mathrm{H}_{2} \mathrm{SO}_{4}$. The condensation process is simulated using a fluid film model which is coupled with the in-cylinder gas phase. Prior to the engine simulations, the fluid film condensation model is validated using the experimental data of sulfuric acid condensation rate in a laminar pipe flow. Next, the engine model is validated against the experimental sulfur dioxide $\left(\mathrm{SO}_{2}\right)$ to sulfur trioxide $\left(\mathrm{SO}_{3}\right)$ conversion obtained from the corresponding test engine. Both of the validation studies show a good agreement with the experimental data. The engine model is then utilized to simulate condensation for different operating conditions. The engine simulation results reveal that the fluid film has a significant effect on the total mass of sulfuric acid vapor and a marginal effect on the total mass of water vapor. A close to linear correlation is found between the fuel sulfur content and the total condensed mass of sulfuric acid. The level of humidity of the scavenging air does not affect the condensation of sulfuric acid considerably, relative to the humidity increase, but it has a high impact on water condensation. The
\end{abstract}


study of the scavenging pressure level reveals a counter intuitive behavior where the condensation rates decrease with higher scavenging pressures due to the flow regime and flame size. Next, increasing the cylinder liner temperature decreases significantly the water condensation contrary to the sulfuric acid condensation which is marginally affected. The increase in lubricant film thickness results in a decrease for both the sulfuric acid and water condensation with a more pronounced reduction for water. Finally, a comparison between the high and low load operating conditions reveals a small drop in the total condensed mass of sulfuric acid and water for the low load conditions.

Keywords: Condensation, Marine diesel engine, Sulfuric acid, Combustion, CFD

\section{Introduction}

The shipping industry is responsible for the majority of the world trade transportation. The main source of propulsion is two-stroke diesel engines due to their high efficiency and reliability. The present configuration of these marine diesel engines utilizes low cost heavy fuel oil (HFO). However, HFO contains a certain level of sulfur (S). During the engine operation, which is normally excessive with air, the fuel sulfur oxidizes to large amounts of sulfur dioxide $\left(\mathrm{SO}_{2}\right)$ and a small portion of $\mathrm{SO}_{2}$ subsequently oxidizes to sulfur trioxide $\left(\mathrm{SO}_{3}\right)$. The latter reacts with water $\left(\mathrm{H}_{2} \mathrm{O}\right)$ and produces sulfuric acid $\left(\mathrm{H}_{2} \mathrm{SO}_{4}\right)$. As the piston moves towards the bottom dead center (BDC) the bulk gas pressure decreases, due to the volume expansion, lowering the dew point temperature of sulfuric acid and water. When the cylinder liner temperature is lower than the aforementioned dew point temperature condensation of sulfuric acid and water on the cylinder liner ensues forming an aqueous solution. This results in cold corrosion which is the leading wear mechanism under these conditions [1, 2]. Cold corrosion degrades the engine efficiency and consumption, see Yahagi 2]. Moreover, it can significantly shorten the life span of vital engine components thus increasing downtime for maintenance and operational costs. As a counter 
measure, the lubricants are enriched with an alkaline reserve of surfactants and limestone in order to neutralize the sulfuric acid, see Sautermeister \& Priest [3]. The lubricant feed rate is also an important parameter against cold corrosion. An optimum feed rate can maximize the refreshing of the lubricant and thus guarantee an adequate alkaline reserve for the sulfuric acid neutralization. Overlubrication can lead to high lubricant consumption (i.e. high operational costs and emissions) and excessive calcium deposits on the piston and piston rings (i.e. high wear and low engine component life) while under-lubrication can lead to mechanical wear and cold corrosion, see Chew \& McGeary [4]. The challenges of calculating an appropriate feed rate are also analyzed by García et al. [5].

Due to the aforementioned reasons, sulfuric acid condensation and cold corrosion for HFO fueled marine engines is an active ongoing research field [6, 7, 8, 9, 10, Nevertheless, there is no open literature to date for engine sulfuric acid condensation simulations using three-dimensional (3D) computational fluid dynamics (CFD) modeling. The previous studies [6, 7, 8, are limited to simplified phenomological models related to the present work and only two CFD simulation studies [11, 12, 13] on unrelated applications. A diesel engine zerodimensional (0D) model of corrosive wear due to sulfuric acid was developed by van Helden et al. [6] without considering the condensation of sulfuric acid. Next, McKinley [7] studied sulfuric acid and water condensation in diesel engine exhaust gas recirculation (EGR) coolers using a 0D model with a simple one reaction chemistry model. The first numerical study concerning the present analyzed problem was carried out by Cordtz et al. 8] who applied a 0D multizone model for a large two-stroke marine diesel engine. The chemical model includes a single hydrocarbon decomposition reaction, a detailed sulfur mechanism and a single reaction for $\mathrm{H}_{2} \mathrm{SO}_{4}$ formation. The condensation of $\mathrm{H}_{2} \mathrm{SO}_{4}$ and $\mathrm{H}_{2} \mathrm{O}$ is simulated with a two-phase vapor liquid equilibrium (VLE) model using activity coefficients derived from the nonrandom two-liquid (NRTL) equation by Renon \& Prausnitz [14]. However, this approach neglects the flow field inside the engine and consequently its mixing effects. For this reason the model compensates by the introduction of a mixing factor thus reducing the robustness of 
the model. Moreover, the model only provides a quantitative outlook on the condensation of sulfuric acid and water but not the spatial distribution of the condensation rate on the cylinder liner.

One of the early attempts to model condensation of sulfuric acid with CFD was performed by Perujo [11, who coupled a commercial CFD solver (ANSYS FLUENT) with a simple VLE condensation model, in order to simulate the condensation of sulfuric/nitric acid and water in boilers. The dew points of the species were calculated in a preprocessing step for specific conditions and used as constants thus decreasing the fidelity of the results. Next, Han et al. 12 introduced a VLE condensation solver using the model of Gmitro \& Vermeulen [15] coupled with ANSYS FLUENT through user defined functions. The purpose of that study was to simulate the condensation of sulfuric acid and water on heat exchanger surfaces. The model was first validated using the experimental measurements of a test case of sulfuric acid condensation in a laminar pipe flow performed by Wilson [16] and reasonably accurate results were obtained. Following validation, the model was applied to study condensation on heat exchangers. The exact same method (from Han et al. [12]) was used by Wang \& Tang [13] for a different heat exchanger geometry.

In the present work, numerical experiments are conducted by modeling the combustion and condensation processes using 3D CFD models. The main goal is to identify the critical parameters which affect sulfuric acid and water condensation on the cylinder liner. This can provide insight into the design parameters that can be taken into account to achieve large two-stroke diesel engines with low levels of cold corrosion and optimal lubricant feed rate. The importance of the engine design parameters, operating conditions and their connection to the lubricant feed rate is highlighted by [4, 5, 17. Additionally, the present study aims to explore the capabilities of the 3D CFD models with respect to condensation coupled with engine combustion simulations which is a topic so far unexplored (to the knowledge of the authors). In the forthcoming sections a description of the main numerical models is presented. A validation study of the fluid film model is then conducted using the experimental measurements of 
a test case of sulfuric acid condensation in a laminar pipe flow performed by Wilson [16] and the numerical results of Han et al. [12]. Upon validation of the fluid film model, the marine diesel engine model is validated against the experimental $\mathrm{SO}_{2}$ to $\mathrm{SO}_{3}$ conversion obtained from the corresponding test engine. Next, a parametric study is performed for different engine operating conditions, which includes the influence of the lubricant film, fuel sulfur content, scavenging air humidity, scavenging pressure, cylinder liner temperature, lubricant film thickness and engine load. Finally, concluding remarks are provided.

\section{Numerical Model}

Condensation is simulated with a fluid film model coupled with a condensation model both of which are provided by STAR-CCM+ version 10 [18. The fluid film model comprises of conservation equations of the mass (Eq. 11), momentum (Eq. 22) and energy (Eq. 33 which are derived with respect to the fluid film thickness $h_{f}$ assuming a parabolic velocity profile across the film [18.

$$
\begin{gathered}
\frac{\mathrm{d}}{\mathrm{d} t} \int_{V} \rho_{f} \mathrm{~d} V+\int_{A} \rho_{f}\left(\mathbf{u}_{f}-\mathbf{u}_{g r}\right) \cdot \mathrm{d} \mathbf{a}=\int_{V} \frac{\dot{m}_{\nu}}{h_{f}} \mathrm{~d} V \\
\frac{\mathrm{d}}{\mathrm{d} t} \int_{V} \rho_{f} \mathbf{u}_{f} \mathrm{~d} V+\int_{A} \rho_{f} \mathbf{u}_{f}\left(\mathbf{u}_{f}-\mathbf{u}_{g r}\right) \cdot \mathrm{d} \mathbf{a}=\int_{A} \mathbf{T}_{f} \cdot \mathrm{d} \mathbf{a}-\int_{A} \rho_{f} \mathrm{~d} \mathbf{a}+\int_{V} \rho_{f} \mathbf{g} \mathrm{d} V \\
\frac{\mathrm{d}}{\mathrm{d} t} \int_{V} \rho_{f} E_{f} \mathrm{~d} V+\int_{A}\left[\rho_{f} H_{f}\left(\mathbf{u}_{f}-\mathbf{u}_{g r}\right)+\mathbf{u}_{g r} p_{f}\right] \cdot \mathrm{d} \mathbf{a}=\int_{A} \dot{Q}_{\nu} \cdot \mathrm{d} \mathbf{a}+\int_{A} \mathbf{T}_{f} \cdot \mathbf{u}_{f} \mathrm{~d} \mathbf{a}+\int_{V} \rho_{f} \mathbf{g} \cdot \mathbf{u}_{f} \mathrm{~d} V
\end{gathered}
$$

Here, $\rho_{f}$ denotes the film density while $\mathbf{u}_{f}$ and $\mathbf{u}_{g r}$ are the film and grid velocity, respectively. For the engine model, the grid velocity represents the cylinder volume expansion which involves deformation of the computational grid. The integrals are with respect to the fluid film volume $V$ and surface area $A$, where $\mathbf{a}=\mathbf{n} A$ is the vector surface area and $\mathbf{n}$ is the unit vector normal to this surface. The fluid film stress tensor is represented by $\mathbf{T}_{f}$ while $\mathbf{g}$ denotes acceleration due to gravity. Moreover, $\dot{Q}_{\nu}$ represents the heat flux at the interface between 
the fluid film and the gas phase. Also, $p_{f}$ denotes the pressure in the film. Finally, $E_{f}$ is the total energy and $H_{f}$ is the total enthalpy of the fluid film [18] described by

$$
\begin{gathered}
E_{f}=H_{f}-\frac{p_{f}}{\rho_{f}} \\
H_{f}=h_{f}-\frac{\left|\mathbf{u}_{f}\right|^{2}}{2} \\
h_{f}=\sum_{i} h_{f, i} Y_{f, i} \\
h_{f, i}=h_{f, i}^{r e f}+\left(T_{f}-T^{r e f}\right) C_{p_{f, i}}
\end{gathered}
$$

where $h_{f}$ and $h_{f, i}$ denote the static enthalpy of the fluid film mixture and of the individual species in the film, respectively. Also, $Y_{f, i}$ is the species mass fraction of the $i$-th species in the film, $h_{f, i}^{r e f}$ is the latent heat of vaporization of the film species, $T_{f}$ is the temperature at the center of the film, $T^{r e f}$ is the standard state reference temperature and $C_{p_{f, i}}$ is the specific heat of the fluid film species.

Additionally, species transport equations (Eq. 8) are utilized for the different species contained in the fluid film.

$$
\frac{\mathrm{d}}{\mathrm{d} t} \int_{V} \rho_{f} Y_{f, i} \mathrm{~d} V+\int_{A} \rho_{f}\left(\mathbf{u}_{f}-\mathbf{u}_{g r}\right) Y_{f, i} \cdot \mathrm{d} \mathbf{a}=\int_{A} \rho_{f} D_{f} \nabla Y_{f, i} \cdot \mathrm{d} \mathbf{a}+\int_{V} \frac{\dot{m}_{\nu, i}}{h_{f}} \mathrm{~d} V
$$

where $\dot{m}_{\nu, i}$ is the condensation rate of the $i$-th species in the film. The molecular diffusion coefficient of the film is represented by $D_{f}=\frac{\nu_{f}}{\sigma_{f}}$ where $\sigma_{f}=1$ and $\nu_{f}$ are molecular Schmidt number and kinematic viscosity of the film, respectively [18.

For the condensation process the built-in condensation model computes iteratively the heat flux $\left(\dot{Q}_{\nu}\right)$ at the interface (subscript $s$ ) between the fluid film and the gas phase by imposing thermal equilibrium

$$
\left.k_{g} \frac{d T}{d y}\right|_{g_{s}}-\left.k_{f} \frac{d T}{d y}\right|_{f_{s}}=\dot{Q}_{\nu}\left(T_{s}\right)
$$


where $k_{g}$ and $k_{f}$ denote the gas and film thermal conductivity, respectively. Moreover, $T_{s}$ is the temperature at the interface between the film and the gas. The temperature gradient in the film is evaluated assuming a linear film temperature profile

$$
\left.\frac{d T}{d y}\right|_{f_{s}} \approx \frac{2}{h_{f}}\left(T_{f}-T_{s}\right)
$$

where $\dot{Q}_{\nu}$ corresponds to

$$
\dot{Q}_{\nu}=\sum_{i}^{N_{\nu}} \Delta H_{i}^{\nu a p} \dot{m}_{\nu, i}
$$

with $\Delta H_{i}^{\nu a p}$ being the species enthalpy of vaporization. Also, the individual components of the condensation rate $\left(\dot{m}_{\nu, i}\right)$ can be calculated using Fick's law 18,19

$$
\dot{m}_{\nu, i}=Y_{g_{s}, i} \dot{m}_{\nu}-\left.\rho_{g_{s}} D_{g s} \frac{d Y_{i}}{d y}\right|_{g_{s}}
$$

with $D_{g s}$ being the molecular diffusion coefficient of the gas defined as $D_{g s}=$ $\frac{\nu_{g s}}{\sigma_{g s}}$ where $\nu_{g s}$ is the laminar kinematic viscosity and $\sigma_{g s}=1$ is the molecular Schmidt number of the gas. Finally, the total condensation rate $\left(\dot{m}_{\nu}\right)$ can be computed by:

$$
\dot{m}_{\nu}=\frac{\dot{Q}_{\nu}+\left.\sum_{i}^{N_{\nu}} \Delta H_{i}^{\nu a p} \rho_{g_{s}} D_{g s} \frac{d Y_{i}}{d y}\right|_{g_{s}}}{\sum_{i}^{N_{\nu}} \Delta H_{i}^{\nu a p} Y_{g_{s}, i}}
$$

The condensation model uses Raoult's law (Eq. 14) to calculate the gas interface species mass fraction $Y_{g_{s}, i}$ by calculating the equivalent gas interface species mole fraction $X_{g_{s}, i}$. Eq. 14 utilizes the gas absolute pressure $P$ at the interface, the species mole fraction in the film $X_{f, i}$ and the saturation pressure of the species $p_{s a t, i}\left(T_{s}\right)$ evaluated at the interface. The main assumption is that the activity coefficient is equal to one $\left(\gamma_{i} \approx 1\right)$ thus the liquid solution is assumed to be ideal.

$$
X_{g_{s}, i} P=\gamma_{i} X_{f, i} p_{s a t, i}\left(T_{s}\right)
$$


To account for the nonideal nature of the sulfuric aqueous solution, the model of Gmitro \& Vermeulen [15] is implemented in the form of user defined functions

$$
\ln \left(p_{s a t, i}\right)=A_{i} \ln \left(298 / T_{s}\right)+B_{i} / T_{s}+C_{i}+D_{i} T_{s}+E_{i} T_{s}^{2}
$$

This model provides the saturation pressures of sulfuric acid and water (index i) as a function of temperature and sulfuric acid concentration in the fluid film (through the tabulated variables $A_{i}, B_{i}, C_{i}$ and $D_{i}$ [15]). A description of the liquid properties of sulfuric acid used in the present study is presented in Table 1 .

Another issue that arises from the nature of the problem is the two condensation regimes as observed by Han et al. [12. By implementing user defined functions the model handles both regimes accordingly as described below.

- Regime 1: The interface temperature $\left(T_{s}\right)$ between the film and the gas is lower than the dew point temperature of sulfuric acid but remains higher than the dew point temperature of water. Under this condition, the sulfuric acid vapor condenses absorbing water along the way. This phenomenon is taken into account by the model of Gmitro \& Vermeulen [15] which results in water condensation even above the dew point temperature of water.

- Regime 2: The interface temperature $\left(T_{s}\right)$ between the film and the gas is lower than the dew point temperature of water. Under this condition, the saturation pressure of water is based on the ideal gas law (Eq. 16) 12 .

$$
p_{\text {sat }}=610.78 \exp \left(17.2694 \frac{T_{s}-273.15}{\left(T_{s}-273.15\right)+238.3}\right)
$$

For more in depth information about the formulation of the fluid film model the reader is referred to 18 .

\section{Fluid Film Model Validation}

The validation of the fluid film model is performed using the experimental measurements of sulfuric acid and water condensation in a laminar pipe flow 
Table 1: $\mathrm{H}_{2} \mathrm{SO}_{4}$ liquid properties

\begin{tabular}{lll}
\hline Property & Value & Reference \\
\hline Molecular weight & $98.07754 \mathrm{~kg} \mathrm{kmol}^{-1}$ & $*$ \\
Density & $1851.671 \mathrm{~kg} \mathrm{~m}^{-3}$ & {$[20]$} \\
Dynamic viscosity & $0.02197 \mathrm{~Pa} \mathrm{~s}^{-1}$ & {$[20]$} \\
Thermal conductivity & $0.33709 \mathrm{~W} \mathrm{~m}^{-1} \mathrm{~K}^{-1}$ & {$[21]$} \\
Heat of formation & $-8.26284 \times 10^{6} \mathrm{~J} \mathrm{~kg}^{-1}$ & {$[20]$} \\
Standard state reference temperature & $298.15 \mathrm{~K}$ & {$[20]$} \\
Specific heat capacity & $1416.6179 \mathrm{~J} \mathrm{~kg}^{-1} \mathrm{~K}^{-1}$ & {$[22]$} \\
\hline
\end{tabular}

* Calculated based on elemental mass

performed by Wilson [16]. A schematic of the experimental setup is shown in Fig. 1. The pipe length is $0.315 \mathrm{~m}$ and its diameter $(D)$ is $0.01 \mathrm{~m}$. At the inlet boundary, a parabolic velocity is assigned using user defined functions with a volumetric flow rate $(\dot{Q})$ of $3.93 \times 10^{-4} \mathrm{~m}^{3} \mathrm{~s}^{-1}$ at temperature $\left(T_{\text {inlet }}\right)$ of $414 \mathrm{~K}$. The inlet flue gas mole fraction of water $\left(X_{\mathrm{H}_{2} \mathrm{O}}\right)$ and sulfuric acid $\left(X_{\mathrm{H}_{2} \mathrm{SO}_{4}}\right)$ is 0.06 and $5 \times 10^{-6}$, respectively. Finally, the wall temperature $\left(T_{\text {wall }}\right)$ remains constant and uniform at $350 \mathrm{~K}$. More details on the experimental setup can be found in 16 .

The numerical model is validated against the experimental measurements of Wilson [16] but it is also benchmarked against the results obtained by the numerical model of Han et al. [12. Comparisons of the results are depicted in Fig. 2(a) and (b). It is clear from the graph that the present model is capable of predicting the condensation of sulfuric acid in good agreement with both the experimental and numerical model results of Wilson [16] and Han et al. [12], respectively. In contrast, the default built-in condensation model (i.e. without the model of Gmitro \& Vermeulen [15] and water absorption effects) using saturation pressure functions of pure water and sulfuric acid components fails to predict condensation. This proves the importance of the saturation pressure prediction. The error of the models compared with the experimental measure- 


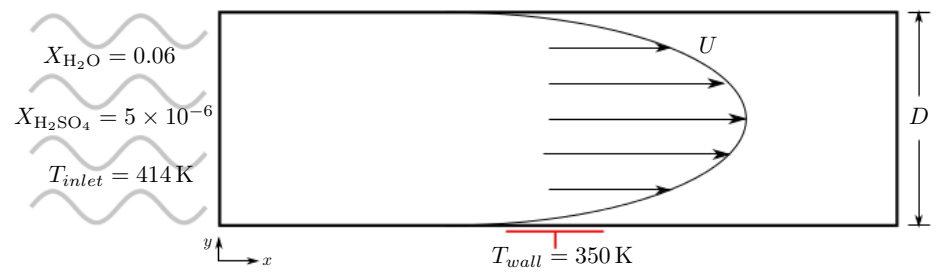

Figure 1: Schematic diagram of the laminar pipe flow of the Wilson [16] experiment and of the boundary conditions used in the present study.

ments of Wilson [16 in Fig. 2[(b) reveals that the current model overpredicts the condensation of sulfuric acid near the pipe inlet, contrary to the model of Han et al. 12] which moderately underestimates the condensation of sulfuric acid at the respective positions. The initial condensation rate spike of the current model at the pipe inlet is due to the imposed uniform species concentration at the pipe inlet boundary. This can be seen in Fig. 2(b) where the error of the current model decreases gradually away from the pipe inlet and after $0.123(\mathrm{~m})$, where the flow is developed, the model predicts better the condensation rate of sulfuric acid compared to the model of Han et al. 12. The aforementioned results are obtained after successfully conducting a mesh convergence study by varying the cell number from 99300 up to 2889920 with a minimum near wall cell thickness of $5 \times 10^{-5} \mathrm{~m}$ to $1.27 \times 10^{-5} \mathrm{~m}$, respectively. The convergence study shows mesh independent results with a maximum difference of $2 \%$ between the meshes. In summary, the present model produces results which are in good agreement with the experimental measurements of Wilson [16] and the numerical results of Han et al. 12. 

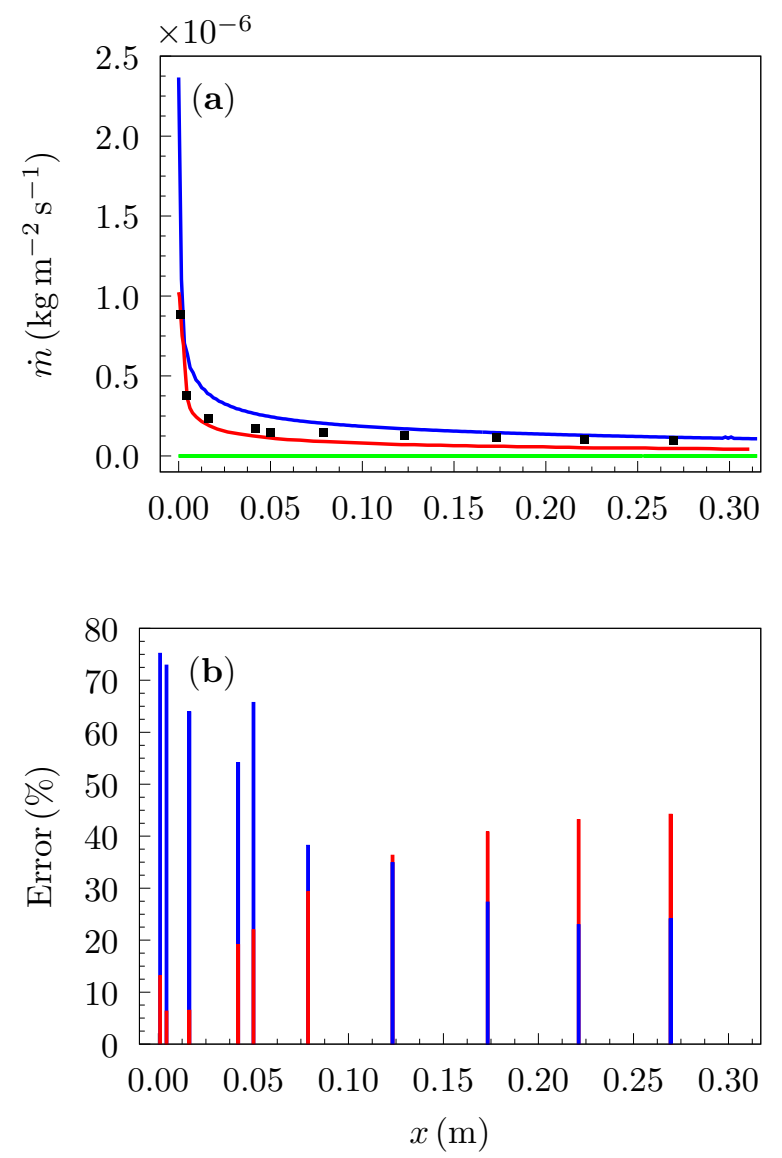

Figure 2: Spatial distribution of (a) sulfuric acid condensation rate $(\dot{m})$ and (b) error against the experimental data of Wilson [16] (-) with respect to the pipe axial position $(x)$, using the current model ( - ) compared with the numerical model of Han et al. 12] ( - ). The default built-in model (i.e. without the model of Gmitro \& Vermeulen [15] using saturation pressure functions of pure water and sulfuric acid components) $(-)$ is presented only for demonstration purposes. 


\section{Marine Diesel Engine Simulations}

The groundwork of these simulations was set by Pang et al. 9] who used a 3D CFD engine model of the 4T50ME-X test engine (situated at MAN Diesel \& Turbo, Denmark) to study the formation of sulfuric oxides $\left(\mathrm{SO}_{\mathrm{x}}\right)$ and $\mathrm{H}_{2} \mathrm{SO}_{4}$ in a large two-stroke marine diesel engine.

The engine model uses an unsteady Reynolds-averaged Navier-Stokes (URANS) Eulerian-Lagrangian approach to simulate the diesel injection and combustion process where the injected fuel is represented by liquid droplets. The primary spray break up process is modeled utilizing a Rosin-Rammler droplet size distribution. For the secondary break up process the Kelvin Helmholtz and Rayleigh Taylor (KHRT) model is applied. Turbulence in the continuous gas phase is modeled using the $k-\omega$ SST model. A skeletal n-heptane mechanism (of 30 species) is combined with a sulfur subset. The latter one is presented in Table 2 . The chemical reactions are coupled to the CFD model with the DARS-CFD solver [18] using the well stirred reactor model. More details on the engine model can be found in Pang et al. [9, 10. In the present work, a modified version of the model by Pang et al. [9, 10] is used in order to accommodate the additional fluid film model. The first modification concerns the near wall mesh resolution with an increased minimum near wall cell thickness of $2.3 \times 10^{-6} \mathrm{~m}$ which is around 5 times coarser than what is used in 9, 10. This change is made for stability reasons for the fluid film model. The second modification regards the time step which is decreased by a factor of 2 (i.e. $2 \times 10^{-6} \mathrm{~s}$ ) in order to achieve stability without compromising efficiency. The initial lubricant film distribution on the cylinder liner is assumed uniform with a thickness of $1 \times 10^{-5} \mathrm{~m}$, see Christiansen et al. 23. The fluid film model is set up to allow condensation only (i.e. no evaporation occurs). The reason behind this choice is that the mechanism that sulfuric acid and water evaporate after they have condensed and mixed or reacted with the lubricant is so far unknown. Moreover, gas phase nucleation and condensation are not considered. In the following sections, the simulation results will be presented. The goal of these results is 
Table 2: Reactions and the Arrhenius parameters of the skeletal sulphur model. Units in mol, $\mathrm{cm}, \mathrm{s}$ and $\mathrm{K}[9]$

\begin{tabular}{llccc}
\hline No. & Reaction & $\mathrm{A}$ & $\mathrm{n}$ & $T_{a}$ \\
\hline 1 & Fuel-S $+\mathrm{O}_{2} \rightarrow \mathrm{SO}_{2}$ & Global step, fast & & \\
2 & $\mathrm{SO}_{2}+\mathrm{O}(+\mathrm{M}) \leftrightarrow \mathrm{SO}_{3}(+\mathrm{M})$ & $3.70 E+11$ & 0.00 & 850 \\
& low-pressure limit & $2.40 E+27$ & -3.6 & 2610 \\
& Troe parameters 0.442, 316, 7442 & & \\
& low-pressure limit $\left(\mathrm{N}_{2}\right)$ & $2.90 E+27$ & -3.58 & 2620 \\
& Troe parameters $\left(\mathrm{N}_{2}\right)$ 0.43, 371, 7442 & & & \\
3 & $\mathrm{SO}_{3}+\mathrm{H} \leftrightarrow \mathrm{SO}_{2}+\mathrm{OH}$ & $8.40 E+09$ & 1.22 & 1670 \\
4 & $\mathrm{HOSO}_{2}+\mathrm{O}_{2} \leftrightarrow \mathrm{HO}_{2}+\mathrm{SO}_{3}$ & $7.80 E+11$ & 0.00 & 330 \\
5 & $\mathrm{SO}_{2}+\mathrm{OH}(+\mathrm{M}) \leftrightarrow \mathrm{HOSO}_{2}(+\mathrm{M})$ & $5.70 E+12$ & -0.27 & 0 \\
& low-pressure limit & $1.70 E+27$ & -4.09 & 0 \\
& Troe parameters $0.10,1 E-30,1 E+30$ & & & \\
& $\mathrm{~N}_{2} / 1 / \mathrm{SO}_{2} / 5 / \mathrm{H}_{2} \mathrm{O} / 5 /$ & & & \\
6 & $\mathrm{SO}_{3}+\mathrm{H}_{2} \mathrm{O} \leftrightarrow \mathrm{H}_{2} \mathrm{SO}_{4}$ & $7.23 E+8$ & 0.00 & 0 \\
\hline
\end{tabular}

to provide the trends for different operating conditions. The total vapor and condensed mass are evaluated quantitatively at 90 crank angle degrees (CAD) after top dead center (ATDC). Contrary, the condensation rates are evaluated qualitatively as a complementary metric to provide better insight. A high load baseline case is used as a reference point throughout this study (unless explicitly stated otherwise) with its main operating conditions listed in Table 3 The engine simulations start from the top dead center (TDC) thus the imposed conditions at this position are referred as initial conditions. The simulations were executed in parallel on three compute nodes. Each node consisted of two 64bit Intel Ivy Bridge Xeon E5-2650 v2 8-core CPUs running at $2.60 \mathrm{GHz}$ with 128 GB of RAM (type DDR3 dual-rank memory) at $1600 \mathrm{MHz}$. The average execution time for the high load cases was around 197 hours. 
Table 3: Engine specifications and operating conditions

\begin{tabular}{ll}
\hline Property & Value \\
\hline Bore & $0.5 \mathrm{~m}$ \\
Stroke & $2.2 \mathrm{~m}$ \\
Liner temperature $\left(T_{\text {lin }}\right)$ & $323 \mathrm{~K}$ \\
Fuel sulfur mass fraction $\left(Y_{\mathrm{S}}\right)$ & $2 \%$ \\
Initial water vapor mass fraction $\left(Y_{\mathrm{H}_{2} \mathrm{O}}\right)$ & $0.5 \%$ \\
Initial pressure $\left(p_{\text {init }}\right)$ & $15.189 \mathrm{MPa}$ \\
Initial temperature $\left(T_{\text {init }}\right)$ & $924 \mathrm{~K}$ \\
Engine speed & $123 \mathrm{rpm}$ \\
Injected fuel mass & $44.6 \mathrm{~g}$ \\
\hline
\end{tabular}

\subsection{Engine Model Validation}

The new engine model (which is coupled with the fluid film model) is first validated against experimental data of $\mathrm{SO}_{2}$ to $\mathrm{SO}_{3}$ conversion $\varepsilon=\left[\mathrm{SO}_{3}\right] /\left(\left[\mathrm{SO}_{2}\right]+\right.$ $\left.\left[\mathrm{SO}_{3}\right]\right)$ from the $4 \mathrm{~T} 50 \mathrm{ME}-\mathrm{X}$ test engine under low load operating conditions. This is because these measurements are not available for full load operating conditions to this date. For the validation study the baseline case has to be modified to simulate the low load operating conditions. Thus, for the low load case the initial pressure and temperature are changed to $p_{\text {init }}=6.67 \mathrm{MPa}$ and $T_{\text {init }}=850 \mathrm{~K}$, respectively. The engine speed is set to $78 \mathrm{rpm}$ and the total amount of injected fuel is reduced by around $50 \%$, see Pang et al. [9]. Fig. 3 shows a good agreement of the $\mathrm{SO}_{2}$ to $\mathrm{SO}_{3}$ conversion $(\varepsilon)$ for both cases. The difference of $\varepsilon$ at $90 \mathrm{CAD}$ ATDC from the average experimental measurements value (with a standard deviation of 0.148 ) is $28 \%$ and $34 \%$ for the cases with and without film, respectively. This illustrates that the overall engine model can capture the trend of the experimental measurements but also that the presence of the film contributes to a better prediction of the $\mathrm{SO}_{2}$ to $\mathrm{SO}_{3}$ conversion. 


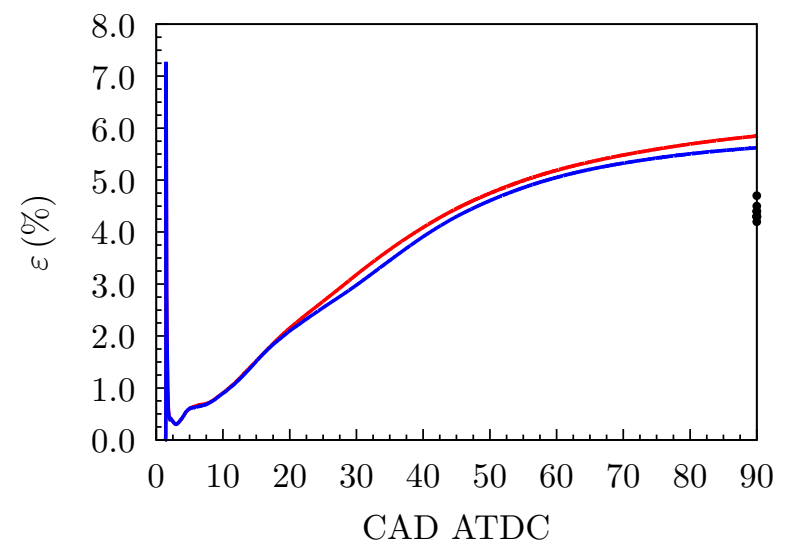

Figure 3: Temporal $\mathrm{SO}_{2}$ to $\mathrm{SO}_{3}$ conversion $(\varepsilon)$ as a function of the crank angle degrees after top dead center (CAD ATDC) an for the low load simulation with film ( - ) and without film $(-)$ against the experimental engine data $(\bullet)$, see Pang et al. [9].

\subsection{Lubricant Film}

Initially, the influence of the lubricant film on the bulk gas phase is examined by considering the baseline case with and without the fluid film model. The results reveal that the total mass of water vapor is not significantly affected by the presence of the lubricant film with a difference between the two cases of less than two percent. In contrast, the total mass of sulfuric acid vapor decreases by $24 \%$ when the fluid film model is active (condensation occurs) as depicted in Fig. 4 This shows that the lubricant film and condensation have a significant effect on the total mass of sulfuric acid vapor and a marginal effect on the total mass of water vapor. Thus the presence of the film is important for the overall prediction of reacting condensable species.

\subsection{Fuel Sulfur Content}

The effect of sulfur content in the fuel is examined by varying its mass fraction $\left(Y_{\mathrm{S}}\right)$ from $2 \%$ to $0.5 \%, 1.0 \%$ and $4.5 \%$. These values are inspired from past and future legislation rules concerning the fuel properties in Emission Control Areas (ECA) 24. Fig. 5(a) illustrates the total mass of sulfuric acid and water vapor as a function of the crank angle degrees after top dead center 


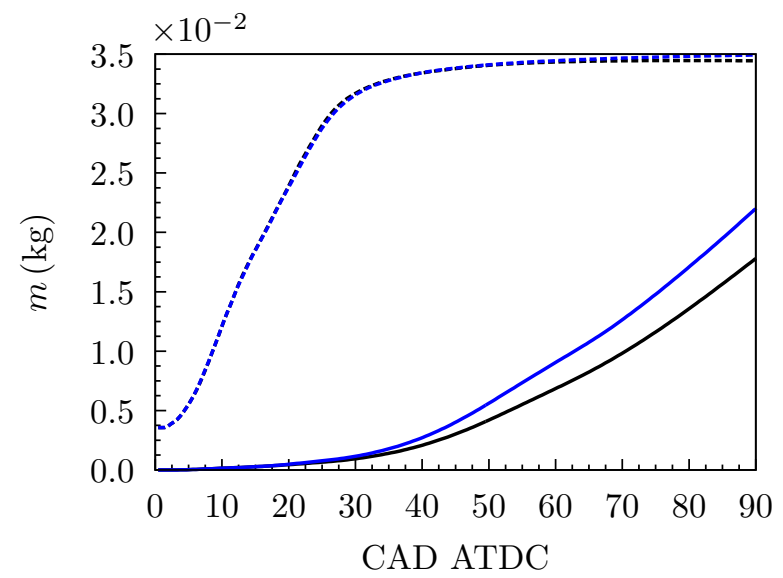

Figure 4: Total vapor mass $m_{\mathrm{H}_{2} \mathrm{SO}_{4}} \times 10^{4}$ (solid lines) and $m_{\mathrm{H}_{2} \mathrm{O}}$ (dashed lines) as a function of the crank angle degrees after top dead center (CAD ATDC) for the baseline simulation with film (-) and without film (-).

(CAD ATDC) for different sulfur content in the delivered fuel. The total mass of sulfuric acid vapor increases almost linearly with respect to the fuel sulfur content due to the increase of the sulfur oxidization products $\mathrm{SO}_{2}$ and $\mathrm{SO}_{3}$ as presented by Pang et al. 9]. In contrast, the total mass of water vapor is almost unaffected by the fuel sulfur content. The slight decrease of the total mass of water vapor for the case with $Y_{\mathrm{S}}=4.5 \%$ can be attributed to the higher amount of $\mathrm{SO}_{3}$ that consumes more $\mathrm{H}_{2} \mathrm{O}$ through the infinitely fast reaction, $\mathrm{SO}_{3}+\mathrm{H}_{2} \mathrm{O} \leftrightarrow \mathrm{H}_{2} \mathrm{SO}_{4}$ (reaction number 6 in Table 2). The same trends are observed in the condensation rates and the total condensed mass in Fig. 5(b) and (c), respectively. It is clear from the results that the correlation between the fuel sulfur content and the resulting total vapor and condensed mass of sulfuric acid is almost linear.

\subsection{Scavenging Air Humidity}

To study the effect of the humidity level of the scavenging air on the condensation of sulfuric acid and water, the initial water vapor concentration in the cylinder of the baseline case is increased by a factor of 4,8 and 16 , respectively. Fig. 6(a) depicts the total mass of water and sulfuric acid vapor as a function of 

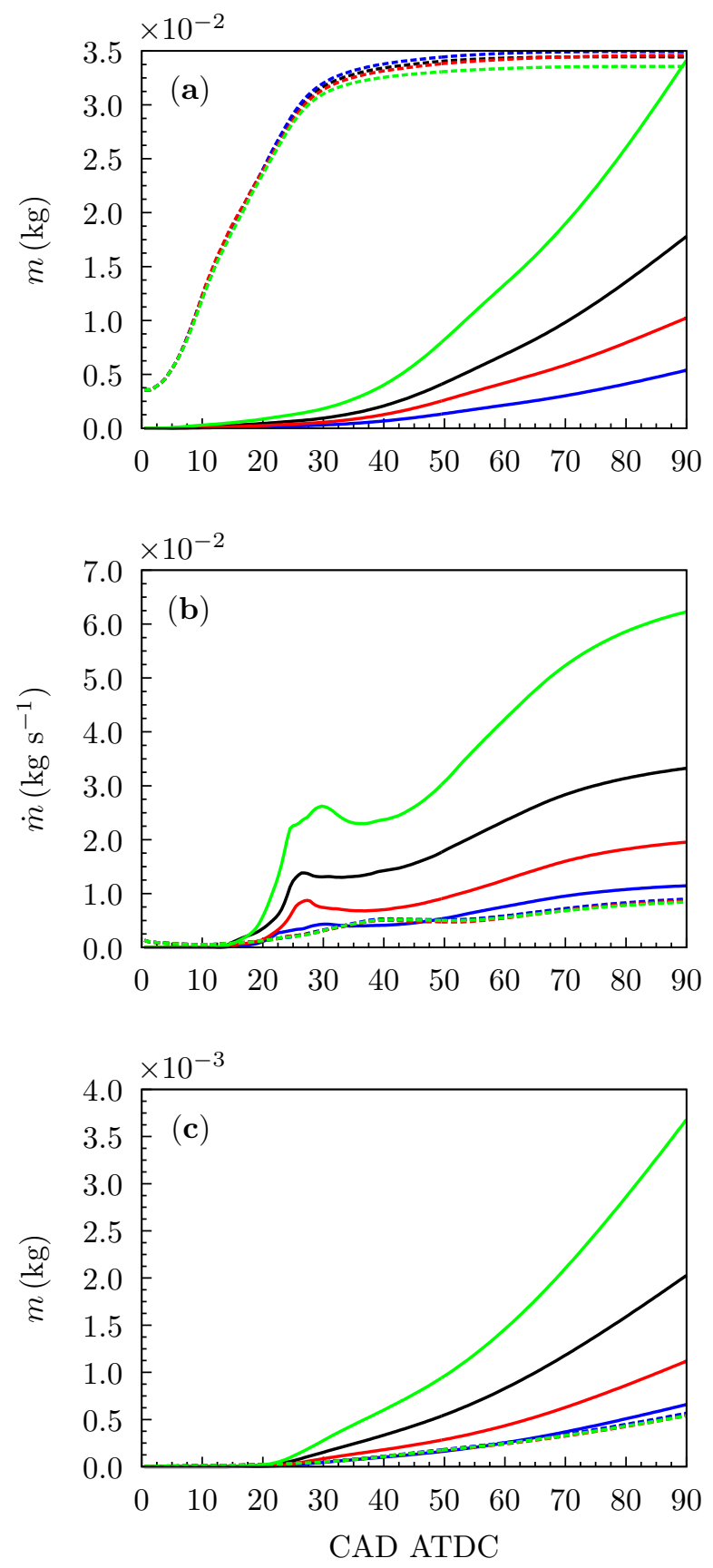

Figure 5: Temporal evolution of (a) total vapor mass $m_{\mathrm{H}_{2} \mathrm{SO}_{4}} \times 10^{4}$ (solid lines) and $m_{\mathrm{H}_{2} \mathrm{O}}$ (dashed lines), (b) condensation rate $\dot{m}_{\mathrm{H}_{2} \mathrm{SO}_{4}} \times 10^{3}$ (solid lines) and $\dot{m}_{\mathrm{H}_{2} \mathrm{O}}$ (dashed lines), (c) total condensed mass $m_{\mathrm{H}_{2} \mathrm{SO}_{4}} \times 10^{3}$ (solid lines) and $m_{\mathrm{H}_{2} \mathrm{O}}$ (dashed lines) for fuel sulfur mass fraction $Y_{\mathrm{S}}=0.5 \%(-), Y_{\mathrm{S}}=1.0 \%(-), Y_{\mathrm{S}}=2.0 \%(-)$ and $Y_{\mathrm{S}}=4.5 \%(-)$. 
the crank angle degrees after top dead center (CAD ATDC). The result shows that the total mass of water vapor increases by $29 \%, 66 \%$ and $139 \%$, respectively. The total mass of sulfuric acid vapor increases by $36 \%, 91 \%$ and $150 \%$. However, Fig. 6(b) and (c) reveal that, while the initial water vapor content has an impact on the production of sulfuric acid, it does not significantly affect its condensation rate and its associated total condensed mass (relative to the initial water content increase). On the contrary, the total condensed mass of water increases by $102 \%, 255 \%$ and $559 \%$ for the three cases, respectively. This behavior can be explained by the higher water vapor concentration which leads to higher water partial pressures and consequently to a higher dew point temperature. This can be verified by Fig. 7 which illustrates the percentage of the cell faces of the discretized film using the condensation Regime 2 (i.e. the cell faces being below water dew point temperature). It is clear from the graph that the cell face percentage increases as the initial water content increases compared to the baseline case.

\subsection{Scavenging Pressure}

The influence of the scavenging pressure $\left(p_{\text {scav }}\right)$ in the engine is also tested by varying the baseline case initial pressure $\left(p_{\text {init }}\right)$ at TDC by $\pm 20 \%$. As expected, the total mass of both sulfuric acid and water vapor increases with $p_{\text {init }}$ as shown in Fig. 8(a). However, the condensation results indicate a counter intuitive behavior as shown in Fig. 8(b) and (c) where the condensation rate decreases when $p_{\text {init }}$ increases. This can be attributed to the high pressure conditions that decrease the flame size. Fig. 9 and Fig. 10 provide the contour plots of temperature and $\mathrm{SO}_{3}$ mole fraction $\left(X_{\mathrm{SO}_{3}}\right)$, respectively, which are shown on cross section planes located at the center of mass of the $\mathrm{SO}_{3}$ cloud. It is clear from the contour plots that the flame structure of the high pressure case is more compact than that in the low pressure case. Consequently, the flame in the low scavenging pressure case impinges the cylinder wall earlier and covers more area than that in the high pressure case. This feeds the near wall area with higher quantities of $\mathrm{SO}_{3}$ (Fig. 10 leading to higher $\mathrm{H}_{2} \mathrm{SO}_{4}$ concentration near the wall 

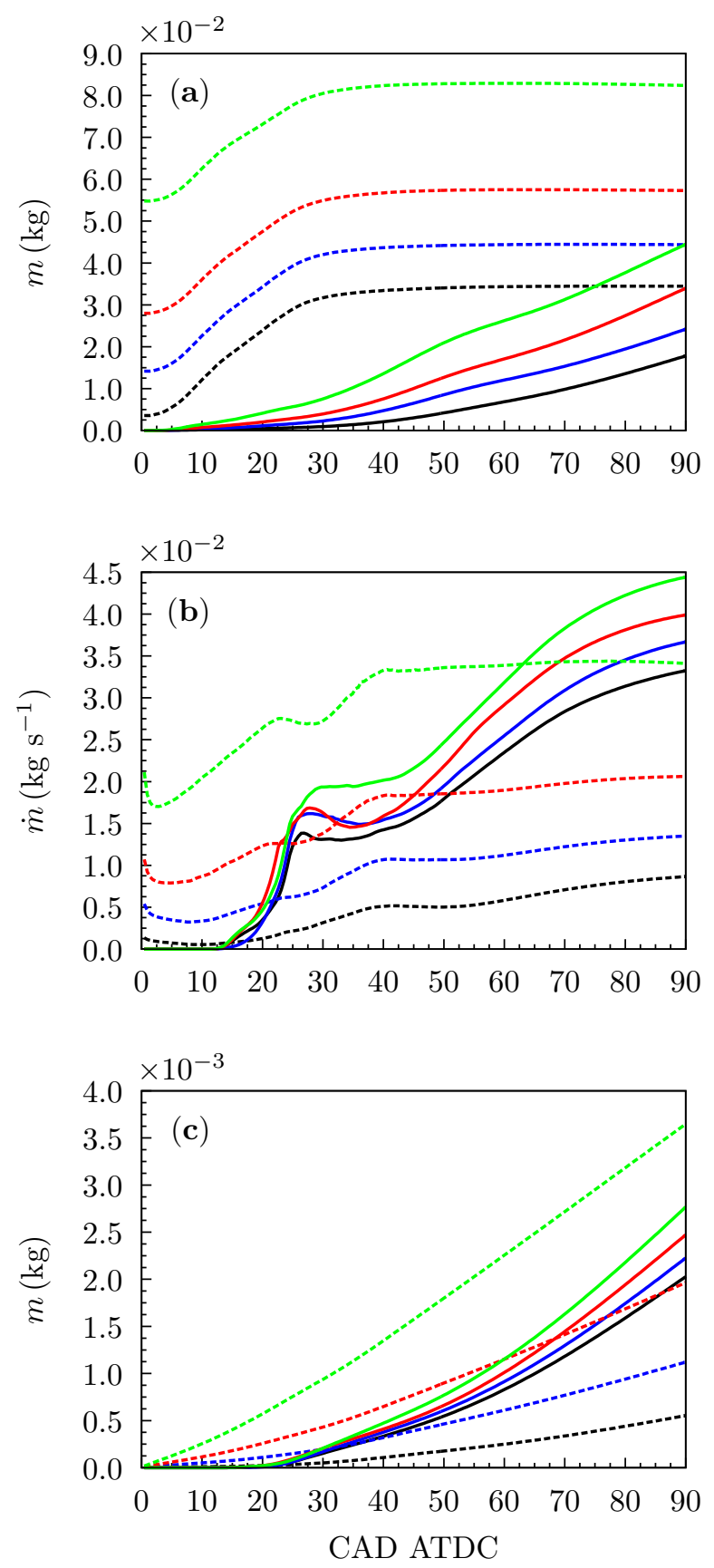

Figure 6: Temporal evolution of (a) total vapor mass $m_{\mathrm{H}_{2} \mathrm{SO}_{4}} \times 10^{4}$ (solid lines) and $m_{\mathrm{H}_{2} \mathrm{O}}$ (dashed lines), (b) condensation rate $\dot{m}_{\mathrm{H}_{2} \mathrm{SO}_{4}} \times 10^{3}$ (solid lines) and $\dot{m}_{\mathrm{H}_{2} \mathrm{O}}$ (dashed lines), (c) total condensed mass $m_{\mathrm{H}_{2} \mathrm{SO}_{4}} \times 10^{3}$ (solid lines) and $m_{\mathrm{H}_{2} \mathrm{O}}$ (dashed lines) for initial gas phase mass fraction of $\mathrm{H}_{2} \mathrm{O}$ in the cylinder $Y_{\mathrm{H}_{2} \mathrm{O}}=0.5 \%(-), Y_{\mathrm{H}_{2} \mathrm{O}}=2.0 \%(-), Y_{\mathrm{H}_{2} \mathrm{O}}=4.0 \%$ $(-)$ and $Y_{\mathrm{H}_{2} \mathrm{O}}=8.0 \%(-)$. 


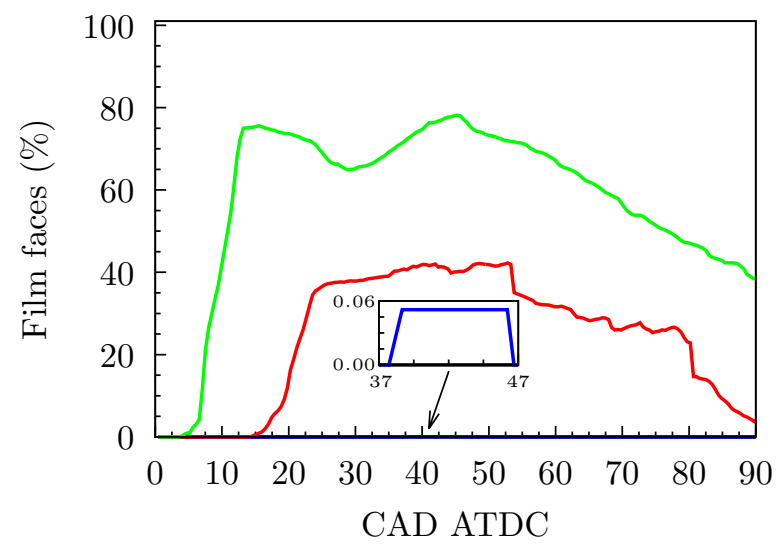

Figure 7: Temporal evolution of the percentage of the discretized film cell faces using the condensation Regime 2 for initial gas phase mass fraction of $\mathrm{H}_{2} \mathrm{O}$ in the cylinder $Y_{\mathrm{H}_{2}} \mathrm{O}=0.5 \%$ $(-), Y_{\mathrm{H}_{2} \mathrm{O}}=2.0 \%(-), Y_{\mathrm{H}_{2} \mathrm{O}}=4.0 \%(-)$ and $Y_{\mathrm{H}_{2} \mathrm{O}}=8.0 \%(-)$.

even though the total mass of sulfuric acid vapor is lower compared to that in the high pressure case. Eventually, the higher sulfuric acid concentration near the wall creates a higher partial pressure and hence a higher condensation rate. Moreover, the onset of the small peak of sulfuric acid condensation at $15 \mathrm{CAD}$ ATDC in the low pressure case, presented in Fig. 8(b), is directly connected to the flame impingement depicted in Fig. 9(c) and Fig. 10.(c). Similarly, the condensation rate of the high pressure case is almost two orders of magnitude lower compared to that in the low pressure case. This corresponds with the flame not being in contact with the wall in Fig. 9(d) and Fig. 10(d). Finally, it should be noted that this result may be sensitive to changes in the governing flow regime.

\subsection{Cylinder Liner Temperature}

The effect of the cylinder liner temperature $\left(T_{l i n}\right)$ is examined using a uniform temperature distribution on the liner surface of $323 \mathrm{~K}$ and $523 \mathrm{~K}$, respectively. The total mass of sulfuric acid and water vapor as a function of the crank angle degrees after top dead center (CAD ATDC) is illustrated in Fig. 11(a). One can notice that due to the higher temperature of the cylinder liner, the sul- 

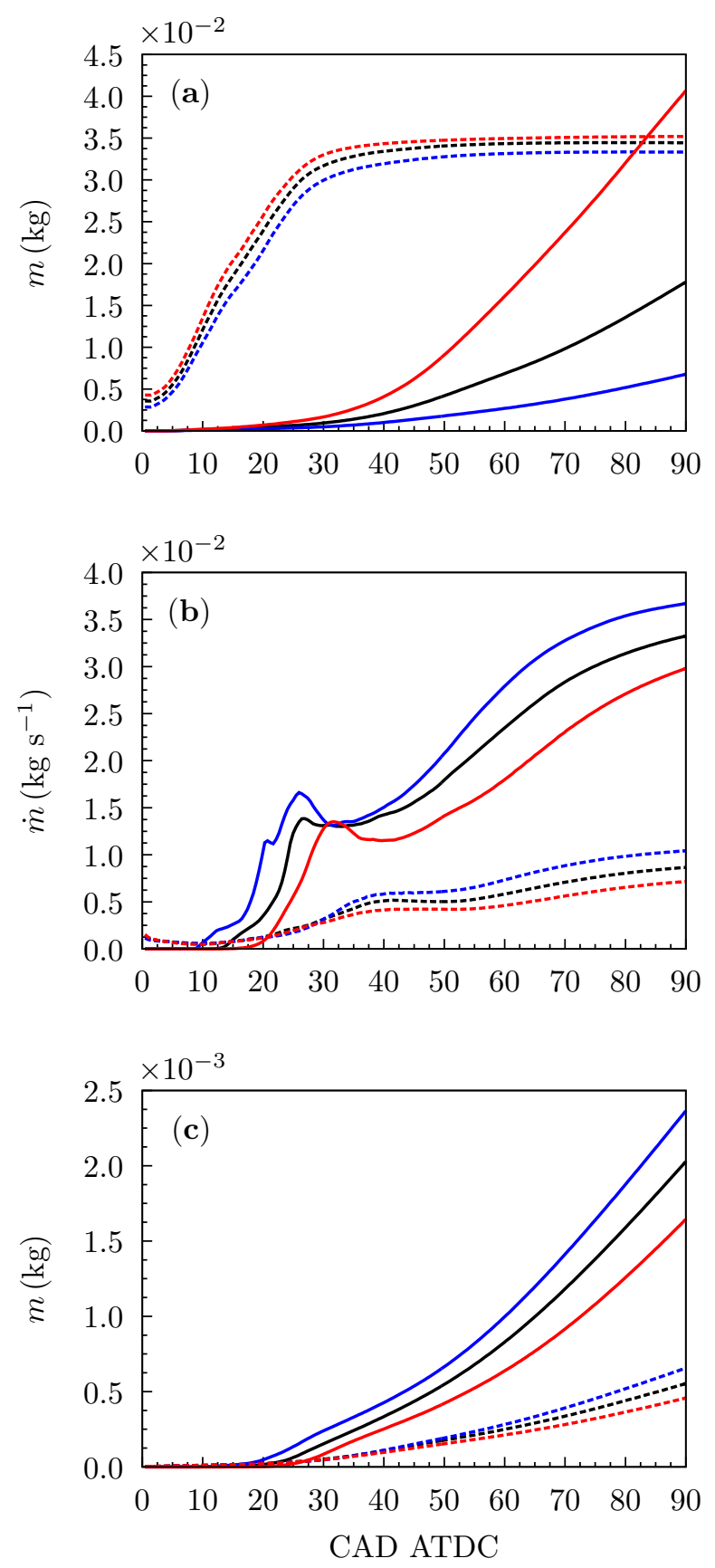

Figure 8: Temporal evolution of (a) total vapor mass $m_{\mathrm{H}_{2} \mathrm{SO}_{4}} \times 10^{4}$ (solid lines) and $m_{\mathrm{H}_{2} \mathrm{O}}$ (dashed lines), (b) condensation rate $\dot{m}_{\mathrm{H}_{2} \mathrm{SO}_{4}} \times 10^{3}$ (solid lines) and $\dot{m}_{\mathrm{H}_{2} \mathrm{O}}$ (dashed lines), (c) total condensed mass $m_{\mathrm{H}_{2} \mathrm{SO}_{4}} \times 10^{3}$ (solid lines) and $m_{\mathrm{H}_{2} \mathrm{O}}$ (dashed lines) for initial cylinder pressure $p_{\text {init }}(-), p_{\text {init }}-20 \%$ (-) and $p_{\text {init }}+20 \%(-)$. 

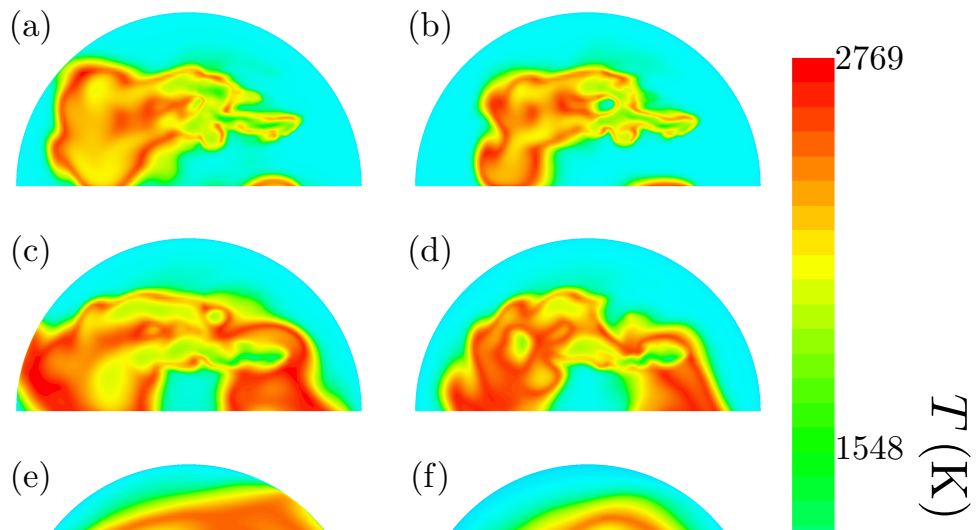

(c)

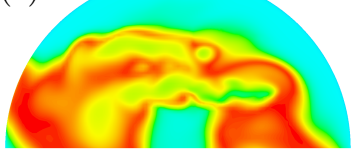

(d)

(e)

(f)
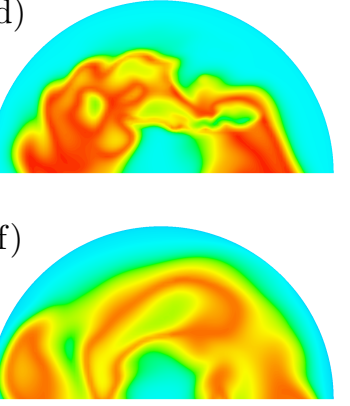

(h)
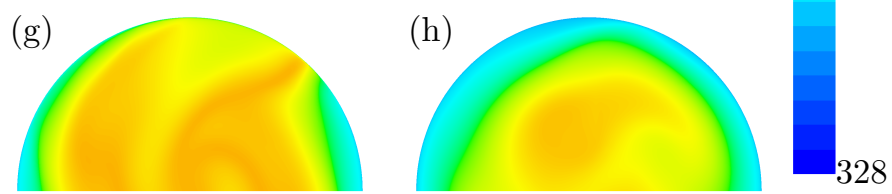

Figure 9: Temperature contour plots of the cylinder cross-section located at the center of mass of the $\mathrm{SO}_{3}$ cloud for $p_{\text {init }}-20 \%$ at (a) 10, (c) 15, (e) 25, (g) 40 CAD ATDC and $p_{\text {init }}+20 \%$ at (b) 10, (d) 15 , (f) 25, (h) 40 CAD ATDC. 

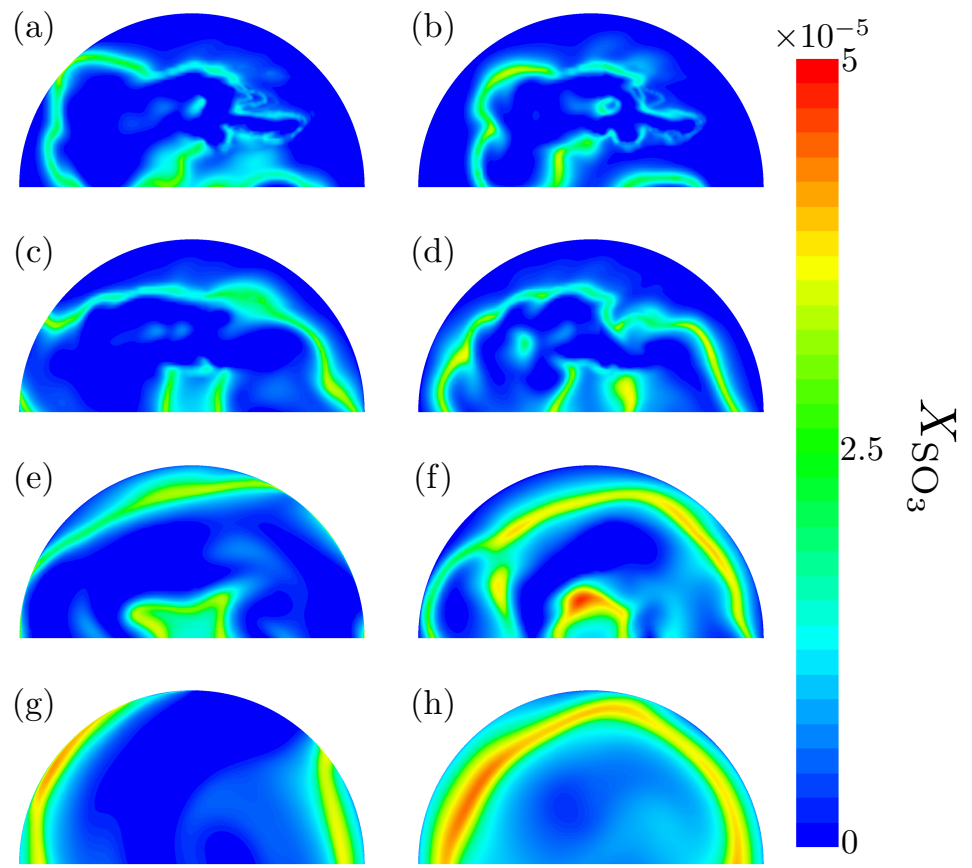

Figure 10: $X_{\mathrm{SO}_{3}}$ mole fraction contour plots of the cylinder cross-section located at the center of mass of the $\mathrm{SO}_{3}$ cloud for pinit $-20 \%$ at (a) 10, (c) 15, (e) 25, (g) 40 CAD ATDC and $p_{\text {init }}+20 \%$ at (b) 10, (d) 15, (f) 25, (h) 40 CAD ATDC. 
furic acid production is limited. This results in a decrease of $24 \%$ of the total mass of sulfuric acid vapor at $90 \mathrm{CAD}$ ATDC. The total mass of water vapor is similar for the two cases. The results in Fig. 11(b) show that the condensation rate of water decreases significantly for the $523 \mathrm{~K}$ case. For instance at 30 CAD ATDC the water condensation rate decreases by $92 \%$. This is because the interface temperature between the lubricant film and the gas is above the dew point temperature of water and below the dew point temperature of sulfuric acid. Hence, the saturation pressure of water switches regime and is evaluated based on a function of temperature and sulfuric acid concentration in the film (i.e. Regime 1). As a consequence, water still condenses on the film but at a low rate. This is reflected on the total condensed mass of sulfuric acid and water on the film, as presented in Fig. 11(c).

\subsection{Lubricant Film Thickness}

The effects of the initial lubricant film thickness are examined by increasing the baseline value $\left(h_{f}=1 \times 10^{-5} \mathrm{~m}\right)$ by a factor of 2.5 and 5 i.e. $h_{f}=2.5 \times 10^{-5} \mathrm{~m}$

and $h_{f}=5 \times 10^{-5} \mathrm{~m}$, respectively. The range of the film thickness values is chosen based on the results of Christiansen et al. 23. Fig. 12(a) illustrates that the total mass of sulfuric acid vapor slightly decreases while the water total vapor mass is almost unaffected. The condensation rate and the total condensed mass of both water and sulfuric acid decrease for higher lubricant film thickness with a more pronounced reduction for water as shown in Fig. 12(b) and (c). This can be attributed to the increased thermal resistance imparted by the increased lubricant film thickness $\left(h_{f}\right)$ cf. Eq. 9 and Eq. 10 .

\subsection{Low Load}

During shipping, the engine operating conditions change depending on the situation and this is the main motivation to study their effects on water and sulfuric acid condensation. For this reason, the baseline case (high load operating conditions) is compared against the low load case, used in the engine validation study. As seen in Fig. 13(a), the sulfuric acid and water total vapor mass in 

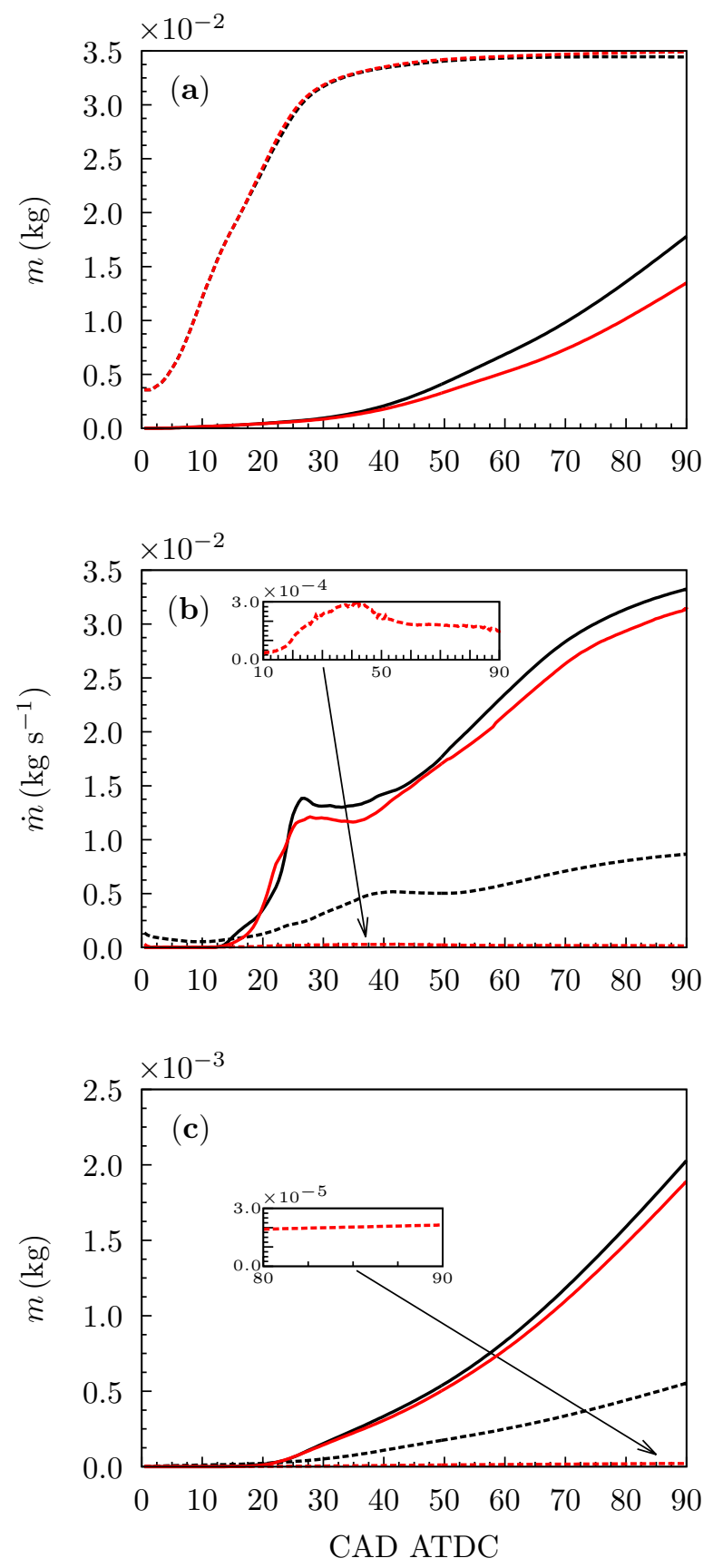

Figure 11: Temporal evolution of (a) total vapor mass $m_{\mathrm{H}_{2} \mathrm{SO}_{4}} \times 10^{4}$ (solid lines) and $m_{\mathrm{H}_{2} \mathrm{O}}$ (dashed lines), (b) condensation rate $\dot{m}_{\mathrm{H}_{2} \mathrm{SO}_{4}} \times 10^{3}$ (solid lines) and $\dot{m}_{\mathrm{H}_{2} \mathrm{O}}$ (dashed lines), (c) total condensed mass $m_{\mathrm{H}_{2} \mathrm{SO}_{4}} \times 10^{3}$ (solid lines) and $m_{\mathrm{H}_{2} \mathrm{O}}$ (dashed lines) for liner temperature $T_{\text {lin }}=323 \mathrm{~K}(\boldsymbol{-})$ and $T_{l i n}=523 \mathrm{~K}(-)$. 

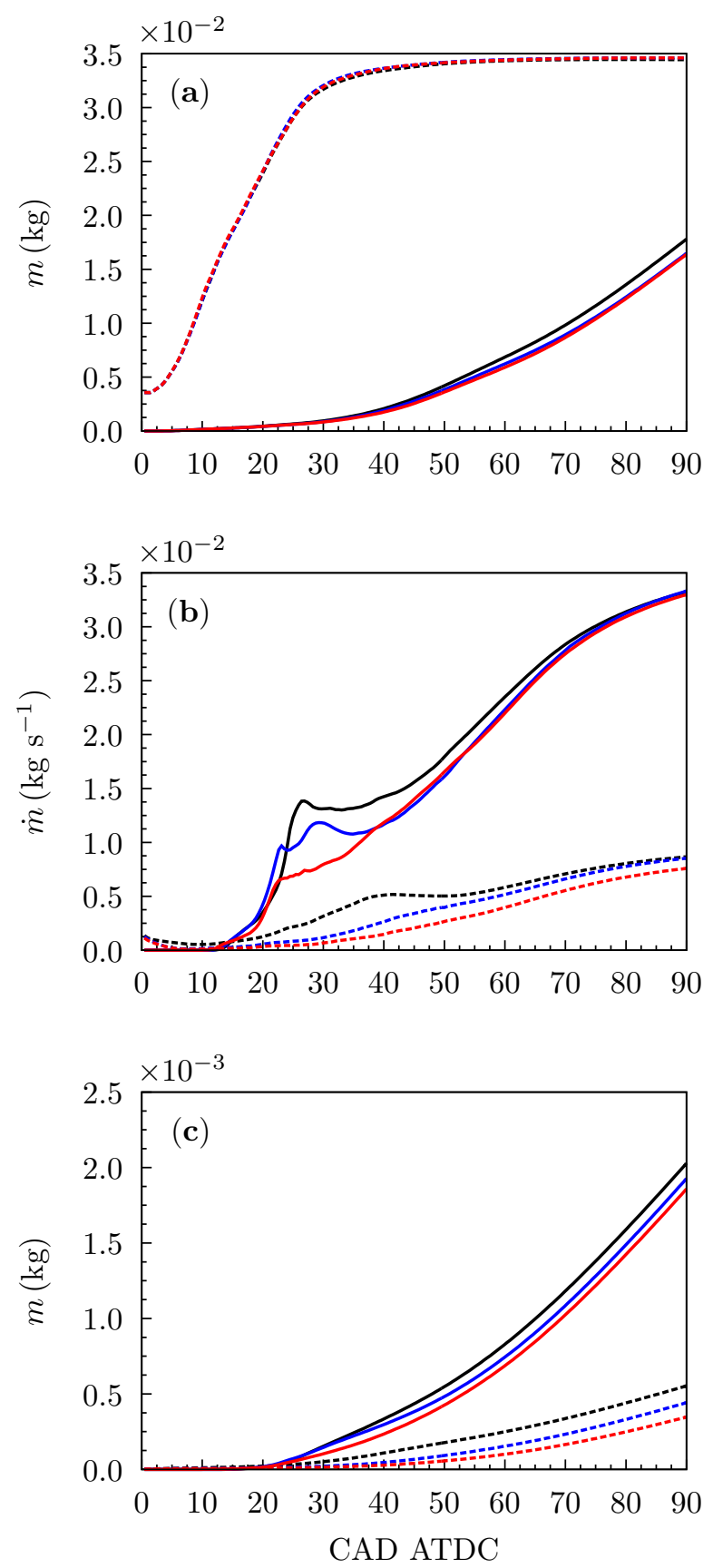

Figure 12: Temporal evolution of (a) total vapor mass $m_{\mathrm{H}_{2} \mathrm{SO}_{4}} \times 10^{4}$ (solid lines) and $m_{\mathrm{H}_{2} \mathrm{O}}$ (dashed lines), (b) condensation rate $\dot{m}_{\mathrm{H}_{2} \mathrm{SO}_{4}} \times 10^{3}$ (solid lines) and $\dot{m}_{\mathrm{H}_{2} \mathrm{O}}$ (dashed lines), (c) total condensed mass $m_{\mathrm{H}_{2} \mathrm{SO}_{4}} \times 10^{3}$ (solid lines) and $m_{\mathrm{H}_{2} \mathrm{O}}$ (dashed lines) for initial lubricant film thickness $h_{f}=1 \times 10^{-5} \mathrm{~m}(-), h_{f}=2.5 \times 10^{-5} \mathrm{~m}(-)$ and $h_{f}=5 \times 10^{-5} \mathrm{~m}(-)$. 
the low load case is reduced by $30 \%$ and $57 \%$, respectively. The condensation rates follow the same trend in Fig. 13(b). Although the condensation rates are significantly lower, especially for sulfuric acid in the low load case, the total condensed mass of sulfuric acid and water reduces by only $29 \%$ and $15 \%$, respectively at 90 CAD ATDC in Fig. 13(c). This is because of the lower piston velocity which leaves the cylinder liner exposed to condensation for a longer period of time. Only for this specific case a numerical instability in the condensation rate of sulfuric acid occurred around the end of the simulation (i.e. 82.8 CAD ATDC). The instability was resolved by decreasing the time step by a factor of two (i.e. $1 \times 10^{-6} \mathrm{~s}$ ) for the rest of the simulation, with less than $0.1 \%$ difference between the stable and unstable simulation results. An overview of all the parametric study results is encapsulated in Table 4 and shows the impact of each parameter on the total vapor and condensed mass of sulfuric acid and water at $90 \mathrm{CAD}$ ATDC compared to the baseline case.

\section{In-Cylinder Phenomena}

The spatial and temporal characteristics of the condensation phenomena on the cylinder liner are examined. Fig. 14 and Fig. 15 present the condensation rate and mass fraction of sulfuric acid and water on the lubricant film for different crank angle degrees after top dead center (CAD ATDC). It is clear that condensation starts early in the combustion cycle, i.e. at 10 CAD ATDC (Fig. 14(b)). The highest condensation rates for both of the species take place between 10 and 45 CAD ATDC (Fig. 14(b) and (h)), due to the high pressure in the cylinder. This results in high concentration of sulfuric acid and water in the lubricant film at the upper part of the cylinder liner, around the piston ring pack position at TDC (Fig. 15), which is consistent with what is observed experimentally [2, 5, 25]. It is worth noting the ellipsoidal area, in Fig. 14(e) and (f), where the sulfuric acid condensation rate is zero while the water condensation rate is high. This area coincides with the location where the flame impinges the cylinder liner resulting in a near wall high temperature region (Fig.16(e)). This 
Table 4: Comparison of the parameter change, using relative difference with respect to the baseline model at 90 crank angle degrees after top dead center (CAD ATDC).

\begin{tabular}{cccccc}
\hline & & \multicolumn{2}{c}{ Total vapor mass } & \multicolumn{2}{c}{ Total condensed mass } \\
\cline { 2 - 6 } Parameter & Variation & $\mathrm{H}_{2} \mathrm{O}$ & $\mathrm{H}_{2} \mathrm{SO}_{4}$ & $\mathrm{H}_{2} \mathrm{O}$ & $\mathrm{H}_{2} \mathrm{SO}_{4}$ \\
\hline Fuel sulfur mass fraction & $-75 \%$ & $\leq \pm 3 \%$ & $-70 \%$ & $\leq \pm 3 \%$ & $-68 \%$ \\
& $-50 \%$ & $\leq \pm 3 \%$ & $-42 \%$ & $\leq \pm 3 \%$ & $-45 \%$ \\
& $+125 \%$ & $\leq \pm 3 \%$ & $+92 \%$ & $\leq \pm 3 \%$ & $+81 \%$ \\
\hline Scavenging Air Humidity & $+300 \%$ & $+29 \%$ & $+36 \%$ & $+102 \%$ & $+10 \%$ \\
& $+700 \%$ & $+66 \%$ & $+91 \%$ & $+255 \%$ & $+22 \%$ \\
& $+1500 \%$ & $+139 \%$ & $+150 \%$ & $+559 \%$ & $+36 \%$ \\
\hline Scavenging pressure & $-20 \%$ & $\leq \pm 3 \%$ & $-62 \%$ & $+19 \%$ & $+17 \%$ \\
& $+20 \%$ & $\leq \pm 3 \%$ & $+128 \%$ & $-17 \%$ & $-19 \%$ \\
\hline Cylinder liner temperature & $+62 \%$ & $\leq \pm 3 \%$ & $-24 \%$ & $-96 \%$ & $-7 \%$ \\
\hline Lubricant film thickness & $+150 \%$ & $\leq \pm 3 \%$ & $-7 \%$ & $-20 \%$ & $-5 \%$ \\
& $+400 \%$ & $\leq \pm 3 \%$ & $-8 \%$ & $-37 \%$ & $-8 \%$ \\
\hline Load & $-75 \%$ & $-57 \%$ & $-30 \%$ & $-15 \%$ & $-29 \%$ \\
\hline
\end{tabular}



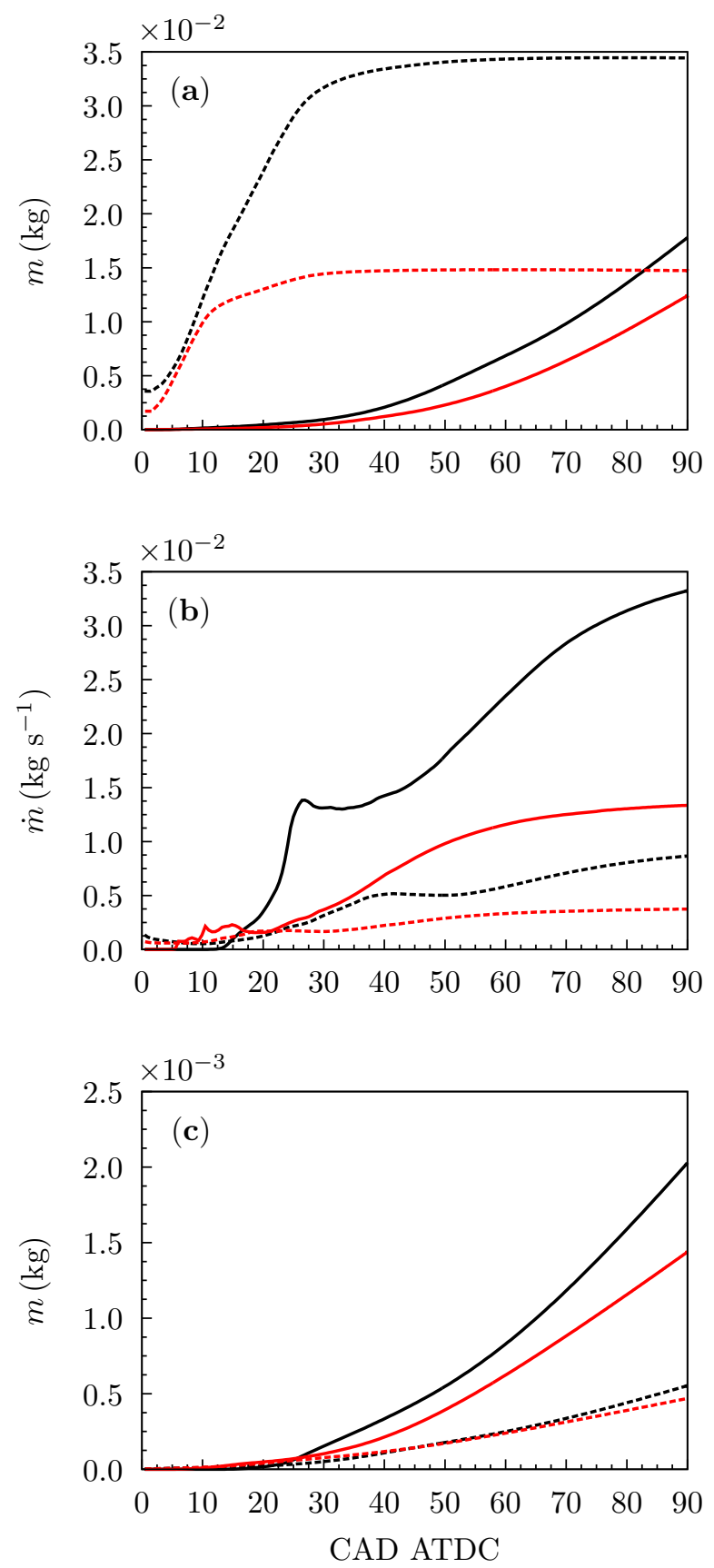

Figure 13: Temporal evolution of (a) total vapor mass $m_{\mathrm{H}_{2} \mathrm{SO}_{4}} \times 10^{4}$ (solid lines) and $m_{\mathrm{H}_{2} \mathrm{O}}$ (dashed lines), (b) condensation rate $\dot{m}_{\mathrm{H}_{2} \mathrm{SO}_{4}} \times 10^{3}$ (solid lines) and $\dot{m}_{\mathrm{H}_{2} \mathrm{O}}$ (dashed lines), (c) total condensed mass $m_{\mathrm{H}_{2} \mathrm{SO}_{4}} \times 10^{3}$ (solid lines) and $m_{\mathrm{H}_{2} \mathrm{O}}$ (dashed lines) for full load (一) and low load (-) operating conditions. 
prevents the formation of $\mathrm{SO}_{3}$ (Fig. 16 (b)) and subsequently $\mathrm{H}_{2} \mathrm{SO}_{4}$ (Fig. 16 (d)), although the concentration of $\mathrm{H}_{2} \mathrm{O}$ and $\mathrm{SO}_{2}$ is high in that area (Fig. 16 (c) and (a)).

\section{Conclusions}

The present work has demonstrated that the proposed fluid film and engine models show a good agreement with the experimental data. For the study involving the large two-stroke marine diesel engine the effects of various parameters of the engine operating conditions are examined. The presence of the fluid film and the resulting condensation have a significant effect on the total mass of sulfuric acid vapor and a marginal effect on the total mass of water vapor. This indicates that condensation is important for the overall prediction of reacting condensable species. Additionally, the fuel sulfur content is found to have an almost linear correlation with the resulting total vapor and condensed mass of sulfuric acid. In contrast, the total vapor and condensed mass of water is not greatly affected by the fuel sulfur content. Moreover, the humidity level of the scavenging air has an impact on the production of sulfuric acid but it does not significantly affect its total condensed mass relative to the humidity increase. Conversely, the total mass of water vapor and its associated total condensed mass are highly affected. The study of the scavenging pressure level reveals a counter intuitive behavior where the condensation rates decrease with higher scavenging pressures. This is attributed to the resulting flame size and flow in the cylinder. Thus, the present $3 \mathrm{D}$ model has a clear advantage against simple phenomenological models because it can capture these flow dependent trends, but also it can provide more details in terms of the spatial distribution of the condensation of sulfuric acid and water (see section 5). Increasing the cylinder liner temperature affects the production of sulfuric acid but has a small influence on its total condensed mass. In contrast, the water condensation rate and its associated total condensed mass decrease significantly as the liner temperature is above the dew point temperature of water and below the dew point 


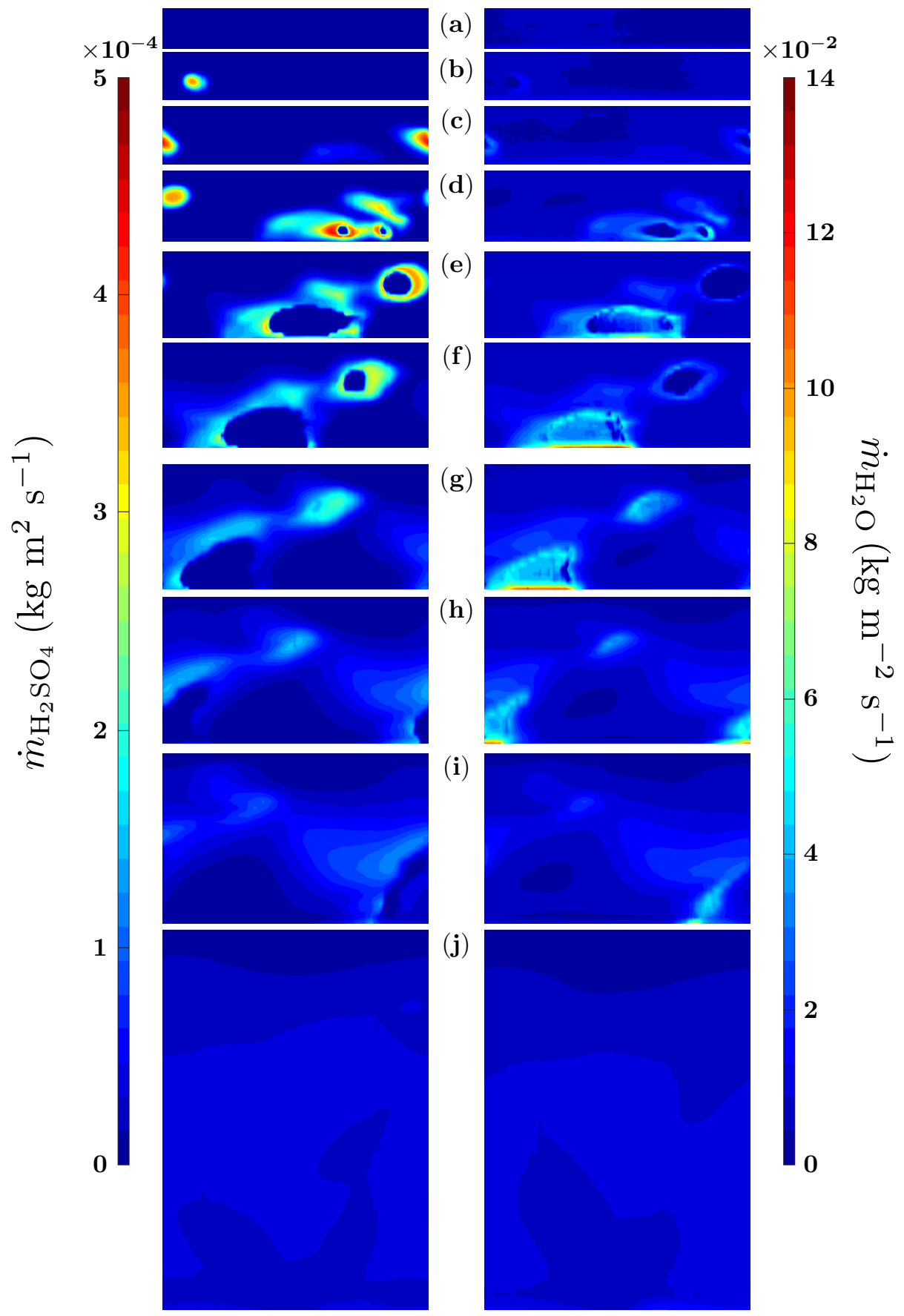

Figure 14: Condensation rate of sulfuric acid $\dot{m}_{\mathrm{H}_{2} \mathrm{SO}_{4}}\left(\mathrm{~kg} \mathrm{~m}^{-2} \mathrm{~s}^{-1}\right)$ (right column) and water $\dot{m}_{\mathrm{H}_{2} \mathrm{O}}\left(\mathrm{kg} \mathrm{m}^{2} \mathrm{~s}^{-1}\right)$ (left column) on the cylinder liner lubricant film at (a) 10, (b) 15, (c) 20, (d) 25, (e) 30, (f) 35, (g) 40, (h) 45, (i) 50, (j) 90 CAD ATDC (baseline case). 


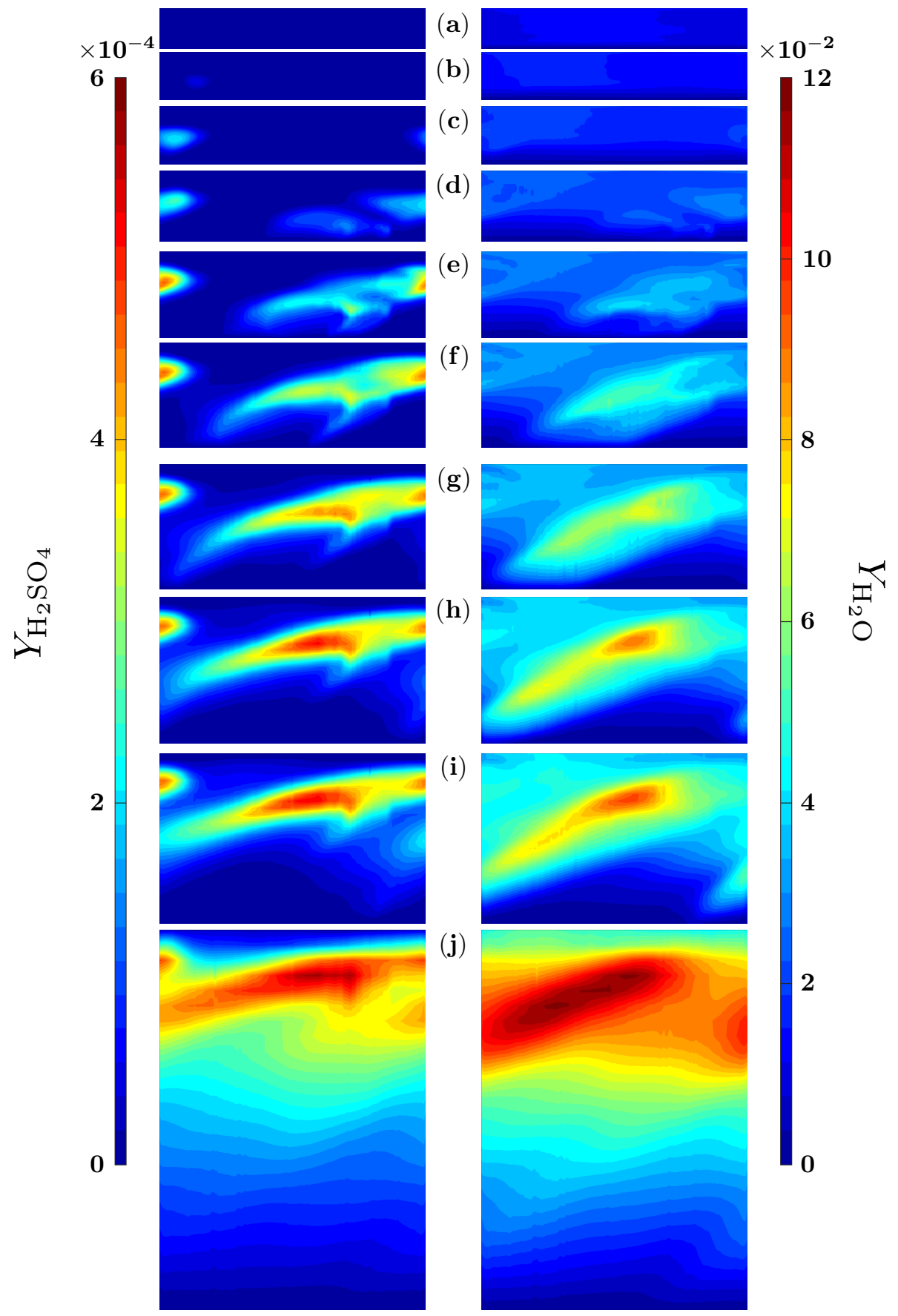

Figure 15: Mass fraction of liquid sulfuric acid $Y_{\mathrm{H}_{2} \mathrm{SO}_{4}}$ (right column) and water $Y_{\mathrm{H}_{2} \mathrm{O}}$ (left column) in the cylinder liner lubricant film at (a) 10, (b) 15, (c) 20, (d) 25, (e) 30, (f) 35, (g) 40, (h) 45, (i) 50, (j) 90 CAD ATDC (baseline case). 
(a)

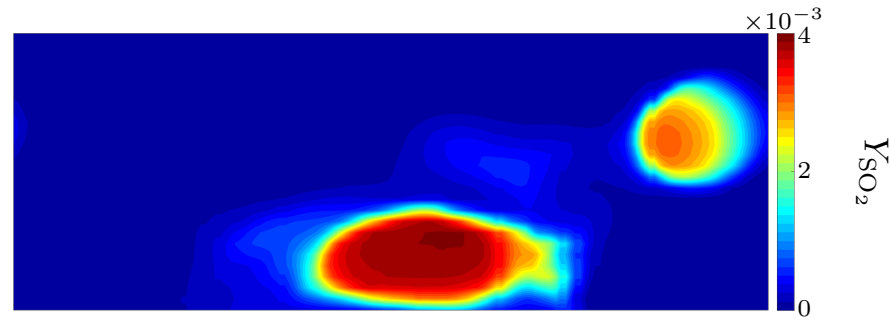

(b)

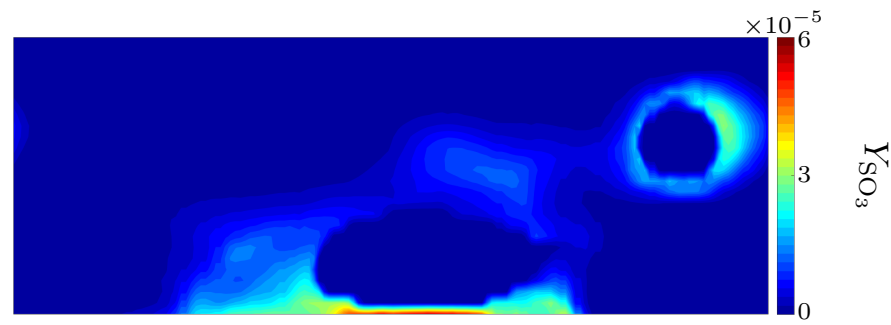

(c)

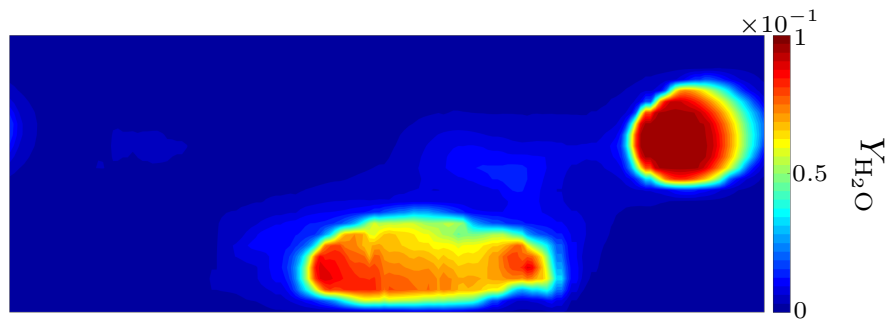

(d)

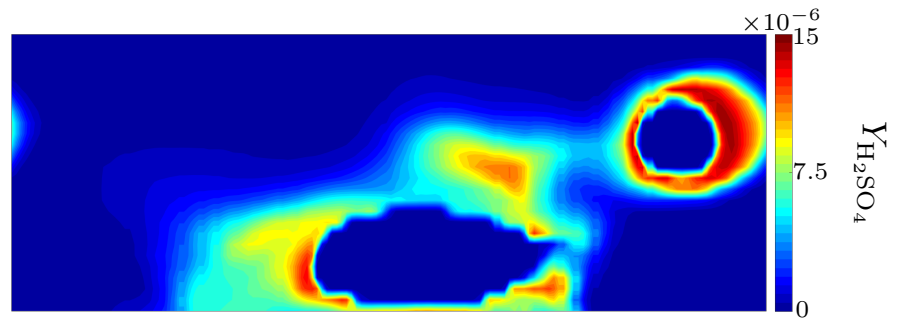

(e)

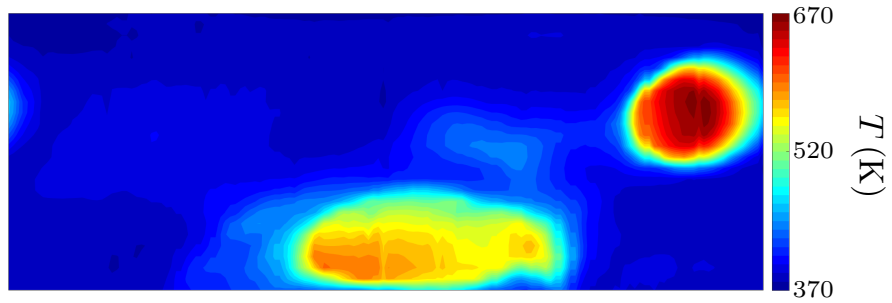

Figure 16: Mass fraction of vapor (a) sulfuric dioxide $Y_{\mathrm{SO}_{2}}$, (b) sulfuric trioxide $Y_{\mathrm{SO}_{3}}$, (c) water $Y_{\mathrm{H}_{2} \mathrm{O}}$, (d) sulfuric acid $Y_{\mathrm{H}_{2} \mathrm{SO}_{4}}$ and (e) temperature $T(\mathrm{~K})$ on the cylinder liner at 30 CAD ATDC (baseline case). 
temperature of sulfuric acid. Nevertheless, water still condenses on the film due to the modeled effect of water absorption during sulfuric acid condensation. Next, an increase in the initial lubricant thickness leads to a decrease for both the sulfuric acid and water condensation with a more pronounced reduction for water. Lastly, the low load operation results in a small reduction of the total condensed mass of sulfuric acid and water, although the decrease of the corresponding condensation rate of sulfuric acid and water is much higher compared to the high load operating conditions. This is due to the lower piston velocity which leaves the cylinder liner exposed to condensation for a longer period of time. In conclusion, the current work identifies the critical parameters which affect sulfuric acid and water condensation on the cylinder liner and thus broadens the knowledge on the design parameters and operating conditions that can be taken into account to achieve large two-stroke diesel engines with low levels of cold corrosion and optimum lubricant feed rate.

\section{Acknowledgements}

The present work is a result based on funding from the Innovation Fund of Denmark and MAN Diesel \& Turbo A/S through the SULCOR project. The

authors wish to thank Rasmus Cordtz from DTU MEK and Adam Peck from CD-adapco.

\section{References}

[1] J. T. Burwell, Jr., Survey of possible wear mechanisms, Wear 1 (2) (1957) 119-141.

[2] Y. Yahagi, Corrosive wear of diesel engine cylinder bore, Tribology Int. 20 (1987) 365-373.

[3] F. A. Sautermeister, M. Priest, Physical and chemical impact of sulphuric acid on cylinder lubrication for large 2-stroke marine diesel engines, Tribol. Lett. 47 (2012) 261-271. 
[4] F. Chew, T. McGeary, Study of the relationship between cylinder lubricant drain condition and performance parameters of 2-stroke cross-head engines, CIMAC, CIMAC, Hamburg, 2001, pp. - .

[5] L. García, S. Gehle, J. Schakel, Impact of low load operation in modern low speed 2-stroke diesel engines on cylinder liner wear caused by increased acid condensation, J. Japan Inst. Mar. Eng. 49 (1) (2014) 100-106. doi: $10.5988 /$ jime.49.100

[6] A. K. van Helden, M. C. Valentijn, H. M. J. van Doorn, Corrosive wear in crosshead diesel engines, Tribology Int. 22 (3) (1989) 189-193. doi: 10.1016/0301-679X (89) 90156-4.

[7] T. L. McKinley, Modeling sulfuric acid condensation in diesel engine egr coolers, in: SAE Technical Paper, SAE International, 1997, pp. -. doi: 10.4271/970636.

URL http://dx.doi.org/10.4271/970636

[8] R. Cordtz, S. Mayer, J. Schramm, S. S. Eskildsen, Characteristics of sulfuric acid condensation on cylinder liners of large two-stroke marine engines, Paper presented at 3rd Rostocker Gromotorentagung, Rostock Germany.

[9] K. M. Pang, N. Karvounis, J. H. Walther, J. Schramm, P. Glarborg, S. Mayer, Modeling of temporal and spatial evolution of sulphur oxides and sulphuric acid under large, two-stoke marine engine-like conditions using integrated CFD-chemical kinetics, Appl. Energy 193 (2017) 63-73.

[10] K. M. Pang, N. Karvounis, J. H. Walther, J. Schramm, Numerical investigation of soot formation and oxidation processes under large two-stroke marine diesel engine-like conditions using integrated CFD-chemical kinetics, Appl. Energy 169 (2016) 874-887.

[11] M. Perujo, Condensation of water vapor and acid mixtures from exhaust gases, PhD dissertation, Technische Universität Berlin (2005). doi:10. 14279/depositonce-893. 
[12] H. Han, Y. L. He, W. Q. Tao, A numerical study of the deposition characteristics of sulfuric acid vapor on heat exchanger surfaces, Chem. Eng. Sci. 101 (2013) 620-630.

[13] Y.-C. Wang, G.-H. Tang, Acid condensation and heat transfer characteristics on h-type fin surface with bleeding dimples and longitudinal vortex generators, Chinese Science Bulletin 59 (33) (2014) 4405-4417. doi:10.1007/s11434-014-0564-3.

[14] H. Renon, J. Prausnitz, Local compositions in thermodynamic excess functions for liquid mixtures, AIChE J. 14 (1) (1968) 135-144.

[15] J. I. Gmitro, T. Vermeulen, Vapor-liquid equilibria for aqueous sulfuric acid, AIChE J. 10 (5) (1964) 740-746.

[16] R. Wilson, Condensation of sulfuric acid and water mixtures in laminar flow, PhD dissertation, Lehigh University (1989).

[17] J. Hammett, Utilising the latest findings on low speed 2-stroke diesel engine oil stress from field \& laboratory engine testing, J. Japan Inst. Mar. Eng. 49 (3) (2014) 293-300. doi:10.5988/jime.49.293.

[18] CD-adapco, Star-ccm+ Documentation, Version 10.06 (2015).

[19] S. Turns, An Introduction to Combustion: Concepts and Applications, McGraw-Hill Education, 2011.

[20] R. Perry, G. D.W.., M. J.O.., Perry's chemical engineers' handbook, McGraw-Hill, 1997.

[21] C. L. Yaws, Transport properties of chemicals and hydrocarbons: Second edition, Transport Properties of Chemicals and Hydrocarbons: Second Edition (2014) 1-715.

[22] A. Burcat, B. Ruscic, Third millenium ideal gas and condensed phase thermochemical database for combustion with updates from active thermochemical tables, Argonne National Laboratory Argonne, IL, 2005. 
[23] J. Christiansen, P. Klit, A. Vølund, J. Hyun-Hwang, Calculation of oil film thickness from damping coefficients for a piston ring in an internal combustion engine, Balttrib'2007 (2007) 162-167.

[24] I. M. Organization, Sulphur oxides (SOx) - regulation 14, http://www.imo. org/en/OurWork/Environment/PollutionPrevention/AirPollution/ Pages/Sulphur-oxides-\%28S0x\%29-\%E2\%80\%93-Regulation-14.aspx.

[25] M. F. Jensen, J. Bøttiger, H. H. Reitz, M. E. Benzon, Simulation of wear characteristics of engine cylinders, Wear 253 (9) (2002) 1044-1056. doi: 10.1016/S0043-1648(02)00251-X 